\title{
Sauvignon Blanc Wine: Contribution of Ageing and Oxygen on Aromatic and Non-aromatic Compounds and Sensory Composition : A Review
}

\author{
C. Coetzee, W.J. du Toit* \\ Department of Viticulture and Oenology, Private Bag X1, Stellenbosch University, Matieland 7602, South Africa \\ E-mail addresses: coetzee@sun.ac.za; wdutoit@sun.ac.za
}

Submitted for publication: April 2015

Accepted for publication: August 2015

Key words: Sauvignon blanc, ageing, oxidation, aromatic compounds

\begin{abstract}
Oxidation and the capacity for sufficient ageing potential of white wines are constant problems for winemakers worldwide. In general, it is accepted that certain grape varieties are especially sensitive to oxidation, suggesting that some of the chemical components key to their sensory attributes are strongly modulated by oxygen exposure. Sauvignon blanc is a well-documented example of an oxygen-sensitive wine, and understanding the stability of various compounds is crucial in order to preserve the fresh and fruity characters of Sauvignon blanc wines while preventing the formation of off-odours over a long period of time. Compounds such as the volatile thiols and methoxypyrazines are key aroma compounds responsible for the typical Sauvignon blanc aroma, while other aroma compounds, such as esters, alcohols and acids, can also contribute to the wine aroma. Oxidation-related compounds (such as aldehydes) can occur under certain conditions and it is essential to understand the chemistry behind oxidation to control and manage the development of various characteristics in wine. The sensory interactions occurring between various compounds (both aromatic and non-aromatic) are also important due to enhancing or suppressive effects that can mask certain aroma nuances. This review focuses on the stability of certain compounds of Sauvignon blanc wines during oxidation and ageing and how it affects the aromatic and non-aromatic composition of these wines.
\end{abstract}

\section{ABBREVIATIONS}

3MH: 3-mercaptohexan-1-ol; 3MHA: 3-mercaptohexan-1-ol acetate; 4MMP: 4-mercapto-4-methylpentan-2one; IBMP: 3-isobutyl-2-methoxypyrazine; GSH: glutathione; GRP: grape reaction product; MeSH: methyl mercaptan; DMS: dimethyl sulphide; 5-HMF: 5-hydroxymethylfurfural; 5-MF: 5-methylfurfural

\section{INTRODUCTION}

Aroma is an important factor in the quality of all foods, but in wines the aroma is probably one of the most important aspects contributing to the overall quality. A large number of chemical compounds with different volatilities and polarities are responsible for the aroma of wine (Arrehnius et al., 1996) and, during winemaking and ageing, various reactions and interactions occur that can influence the perception of the wine bouquet.

One of the most important oenological problems in winemaking is premature wine oxidation, particularly the oxidative spoilage of young white wines. With the exception of sherry and sherry-like wines, white wine quality, in general, will decrease with oxidation (Singleton et al., 1979).
This oxidation can take place in a short amount of time during which a significant loss of fresh and fruity aroma takes place, followed by a colour change as well as the development of unwanted oxidation odours.

Aroma attributes that develop due to the formation of new oxidation compounds have been described as honeylike, farmfeed, hay, woody-like, toasted, dry fruits, caramel, overripe fruit, apple, oxidised apple, acetaldehyde, cooked, aldehyde and liquor (Toukis, 1974; Noble et al., 1987; Renouil, 1988; Halliday \& Johnson, 1992; Chrisholm et al., 1995; Escudero et al., 2002; Silva Ferreira et al., 2002b). These types of unpleasant descriptors are unwanted in wines, and winemakers go to great lengths to avoid the formation of the chemical compounds responsible for these attributes.

*Corresponding author: E-mail addresses: wdutoit@sun.ac.za

Acknowledgements: Winetech and THRIP are thanked for financial support 
Young wines contain high concentrations of oxygenreactive species, triggering a chain of chemical reactions and consequently altering the wine content. Various closure permeability studies have been performed to assess the effect of oxygen and ageing on the quality of young white wines (Godden et al., 2001; Brajkovich et al., 2005; Lopes et al., 2005; Skouroumounis et al., 2005a). Generally speaking, the conclusion of these studies is that less permeable closures allow better preservation of the fresh and fruity character of the wine, presumably by preventing the oxidative loss of pleasant aroma compounds (Lopes et al., 2009).

Too little oxygen exposure has been associated with 'reductive' off-odours. Closures not allowing sufficient oxygen ingress could lead to the formation of the compounds contributing to the 'reductive' aroma (Godden et al., 2001; Skouroumounis et al., 2005a; Kwiatkowski et al., 2007; Lopes et al., 2009). Conversely, oxidative loss of aromatic compounds and the evolution of undesirable aroma compounds will occur with excessive oxygen exposure. Fig. 1 shows the evolution of aroma compounds during the ageing of wines exposed to low and high oxygen concentrations.

It can be concluded that a moderate degree of oxygen exposure allows the expression of optimal aroma attributes (Brajkovich et al., 2005; Lopes et al., 2009; Ugliano et al., 2009; Nygaard et al., 2010); however, the actual degree of oxygen exposure that is necessary to achieve this has not been determined. Very few such studies on Sauvignon blanc wine have actually included precise oxygen measurements (Brajkovich et al., 2005; Lopes et al., 2009; Ugliano et al., 2011), thus still making it difficult to define how much oxygen would be beneficial for wine during bottle ageing. The type (variety and composition) and style (winemaking practices such as wood contact) of the wine are also expected to play a crucial role in the amount of oxygen required to achieve the ideal wine.

While the chromatic changes during wine ageing are well documented, little is known about the aromatic deterioration in relation to white wine oxidation, even though it seems to take place prior to discoloration (Li et al.,
2008). Other than that, studies investigating the oxidative spoilage of wines were often carried out under conditions accelerating oxidation, such as high oxygen exposure or high temperatures (Ferreira et al., 1997; Escudero et al., 2000a; 2002). Conversely, oxidative processes taking place during ageing are usually rather mild and the significance of such levels of oxidation on a wide range of chemical compounds and sensory profile of the wines remains to be established. The interactions between aroma compounds present at any one time in the wine during bottle ageing could also significantly influence the wine's character by changing the perception of certain attributes and should be investigated. This review will focus on the various wine constituents of a typical Sauvignon blanc wine and subsequent oxidation reactions. Sensory aspects and interactions between aromatic compounds will also be discussed.

\section{WHITE WINE OXIDATION}

\section{Oxygen during wine processing}

During winemaking, the grape must and wine are exposed to different levels of oxygen. Macro-oxygenation refers to higher amounts of oxygen being dissolved during winemaking processes such as pump-overs during fermentation, while micro-oxygenation occurs during barrel ageing, for instance, and nano-concentrations (even lower concentrations of dissolved oxygen) could be obtained during bottle ageing. Any oenological practices involving air undoubtedly will cause oxygen dissolution and wines saturated with oxygen will contain about $8 \mathrm{mg} / \mathrm{L}$ oxygen at cellar temperatures and atmospheric pressure (Singleton et al., 1985). Wine is capable of consuming a considerable amount of dissolved oxygen (wine constituents react with oxygen), which has been ascribed to the total phenol content and explains why red wine can consume more oxygen than white wine (Rossi \& Singleton, 1966).

The effect of single oenological processes on the level of dissolved oxygen in wines can be classified as 'high enrichment' and 'low enrichment' treatments (Castellari et al., 2004). A study done on over 500 red and white

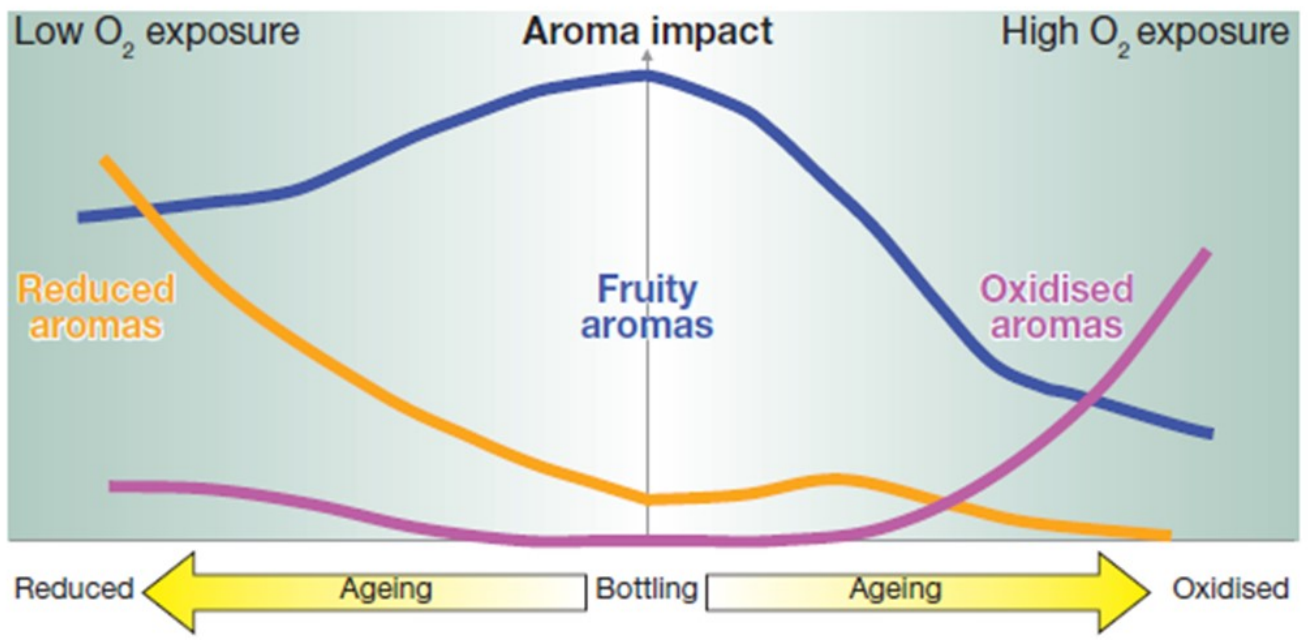

FIGURE 1

The effect of oxygen exposure on the aroma of bottled wine (Ugliano et al., 2010). Reproduced with permission from The Australian Wine Industry Technical Conference Inc. 
wines identified 'high enrichment' practices as racking, centrifugation, refrigeration, continuous tartaric stabilisation and bottling (Castellari et al., 2004). Dissolved oxygen concentration after these treatments ranged from $1 \mathrm{mg} / \mathrm{L}$ to about $8.5 \mathrm{mg} / \mathrm{L}$, with refrigeration and cold stabilisation ranked as the two treatments causing the highest oxygen pickup. 'Low enrichment' treatments are practices like pumping, filtration, heat exchange and electrodialysis, and caused an uptake of up to $0.6 \mathrm{mg} / \mathrm{L}$, with filtration causing the highest oxygen pickup (Castellari et al., 2004). During and after bottling, both wine and the gaseous headspace in the bottle will contain a substantial amount of oxygen. The total packaged oxygen, as the sum of these two components, typically can reach 1 to $9 \mathrm{mg} / \mathrm{L}$ (Ugliano et al., 2013), depending on the specific handling of the wine (care taken to exclude oxygen). In the case of some closures, such as corks or similar products, additional oxygen will be released into the bottle after bottling.

The solubility of oxygen in wine is influenced by the wine composition (e.g., ethanol content), but depends primarily on the temperature and the partial pressure of the gas, with greater solubility at lower temperatures and when pure oxygen is used instead of air (Waterhouse \& Laurie, 2006). The rate of the oxidation reactions, however, increases with increased temperature (Margalit, 1997; Vivas de Gaulejac et al., 2001; Ribéreau-Gayon et al., 2006). The contact of wine with oxygen can be minimised by the use of inert gasses such as nitrogen, carbon dioxide and even argon gas, which can displace the air in a tank or barrel.

\section{Oxygen and phenolics}

Phenolic compounds are characterised by an aromatic ring containing one or more hydroxyl groups $(-\mathrm{OH})$. The concentration of phenolics in white wine will depend on the variety, cultivation conditions, climate, grape maturity, winemaking techniques as well as ageing conditions. The polyphenol content of white wines is substantially lower than that of red wines due to different winemaking techniques favouring phenolic extraction during red wine production. Phenolics are strong hydrogen-donating species, which makes them ideal oxidation substrates (Wilderandt \& Singleton, 1974).

Phenolic molecules originating from grapes can be divided into non-flavonoids and flavonoids. The nonflavonoids are grape-derived and consist, among others, of hydroxybenzoic acids, hydroxycinnamic acids and stilbenes, and are normally the principal phenolic molecules in white wines. Compounds such as the caffeic acid, $p$-coumaric acid and ferulic acid and their tartaric acid esters are examples of hydroxycinnamic acids, and are the main phenolic molecules in white wine that did not receive prolonged periods of skin contact. Of these, trans-caftaric acid and the grape reaction product are the predominant hydroxycinnamate esters in grape juice and wine, together with smaller quantities of coutaric and fertaric acid (Singleton et al., 1978; 1984; Vrhovšek, 1998). The naturally occurring tartaric esters are susceptible to hydrolysis, liberating the corresponding free hydroxycinnamic acids. The hydroxybenzoic acids represent a minor class of white wine polyphenols, of which gallic acid, vanillic acid and syringic acid are a few examples.
The major classes of flavonoids in grapes and wine are flavan-3-ols, flavonols and anthocyanins. Anthocyanin pigments are significant only in red grape varieties and generally are absent from white wines. The main flavan3 -ols found in grapes are (+)-catechin and (-)-epicatechin, as well as the galate ester (-)-epicatechin-3-O-gallate (Tsai Su \& Singleton, 1969), while the flavonols consist mainly of quercetin, kaempferol and myricetin, which are found mainly as glycosides in grapes and as aglycones in wine (Monagas et al., 2005; Ribéreau-Gayon et al., 2006).

In grape must, the enzymatic oxidation of phenolic compounds takes place due to the presence of oxidation enzymes (e.g., polyphenol oxidase), which catalyse the oxidation process, while in wine, non-enzymatic chemical oxidation is the predominant oxidation reaction due to the absence or inhibition of oxidation enzymes. Although polyphenol oxidation is extremely slow (Oszmianski et al., 1985), it affects a wide range of polyphenols, depending on their individual redox potentials (Kilmartin et al., 2002). The oxidation process will depend on a number of factors, such as oxygen concentration, temperature, presence of catalysts, the nature and composition of polyphenols, $\mathrm{pH}$, ethanol content and the presence of antioxidants (Berg \& Akiyoshi, 1956; Cilliers \& Singleton, 1989; Kilmartin et al., 2001; Waterhouse \& Laurie, 2006).

Oxygen in wine is in the unreactive triplet state, and its ability to react directly with most wine components is low (Waterhouse \& Laurie, 2006). The presence of a catalyst (particularly iron and copper) increases the reaction speed by donating an electron to oxygen, resulting in a superoxide ion that exists as a hydroperoxyl radical at wine $\mathrm{pH}$ (Fig. 2). The radical has relatively low reactivity in the wine environment and will react with strong hydrogen-donating species such as phenolic molecules (Wilderandt \& Singleton, 1974). The reaction of the superoxide ion with $o$-diphenols forms $\mathrm{H}_{2} \mathrm{O}_{2}$ and $o$-quinones at wine $\mathrm{pH}$ (Fig. 2).

The $\mathrm{H}_{2} \mathrm{O}_{2}$ can react with ferrous ions via the Fenton reaction to produce a hydroxyl radical, which is extremely reactive and can react with various wine constituents (e.g., alcohols, organic acids and sugars) in proportion to their concentration, causing the formation of aldehydes and ketones. In this case, ethanol will be oxidised primarily to produce acetaldehyde (Waterhouse \& Laurie, 2006). The $o$-quinone is unstable and very reactive and can react further with other molecules with lower redox potentials, such as other phenolic molecules, $\mathrm{SO}_{2}$ and thiol-containing compounds, including glutathione and amino acids. This array of reactions can cause a substantial change in the composition of wine.

\section{The role of antioxidants}

The most common antioxidants (other than phenols) present in wine are sulphur dioxide $\left(\mathrm{SO}_{2}\right)$, ascorbic acid and glutathione (GSH). These compounds interfere in the phenol oxidation process, either by removing oxygen from the wine or by reversing or altering the oxidation process.

Sulphur dioxide is an effective and low-cost additive for the preservation of wines and other food products (Doyle \& Beuchat, 2007). In wine, it serves as the main preservative to prevent oxidation and decrease microbial activity. Even 


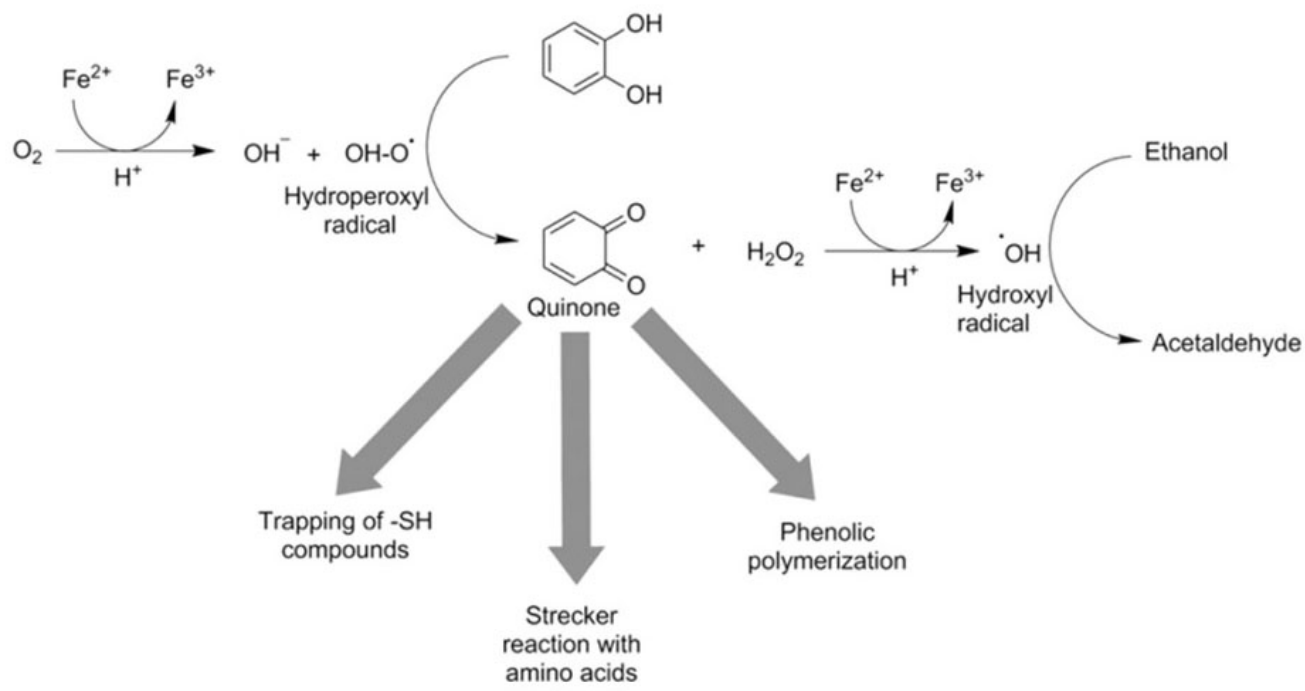

FIGURE 2

Formation of $o$-quinones and hydrogen peroxide and the consequent oxidation of ethanol to form acetaldehyde and other reactions in the wine matrix. Reprinted with permission from Ugliano (2013). Copyright American Chemical Society, 2013.

though $\mathrm{SO}_{2}$ occurs naturally in all wines as a by-product of yeast metabolism during fermentation (Rankine \& Pocock, 1969), it is usually added at several stages in the process of conventional winemaking, such as during crushing, settling or after primary and secondary fermentation (Paul, 1975). Unfortunately, excessive use of $\mathrm{SO}_{2}$ can be detrimental not only to the organoleptic quality of a wine, but also poses a health risk for sensitive consumers (especially asthmatics), and its presence requires mandatory label warning statements in most jurisdictions (Kleinhans, 1982).

Sulphur dioxide exists in wine in both free and bound form (the sum equalling total $\mathrm{SO}_{2}$ ). At wine $\mathrm{pH}(\mathrm{pH} 3$ to 4 ), free $\mathrm{SO}_{2}$ can exist in three forms: molecular $\mathrm{SO}_{2}$, bisulphite $\left(\mathrm{HSO}_{3}{ }^{-}\right)$and sulphite $\left(\mathrm{SO}_{3}{ }^{2-}\right)$. The equilibrium is $\mathrm{pH}$ dependent and is affected by the presence of wine constituents that bind the bisulphite, as well as by wine temperature (UsseglioTomasset, 1992). The molecular form is responsible mainly for antimicrobial properties due to its ability to penetrate the cellular membranes of microorganisms (Beech et al., 1979). However, at wine $\mathrm{pH}$, only a small proportion of the free $\mathrm{SO}_{2}$ is in molecular form, with the predominant form being bisulphite (94 to 99\%), which can bind a large range of wine components, consequently producing bound $\mathrm{SO}_{2}$ (Zoecklein et al., 1995; Oliveira et al., 2002). The sulphite ion can react directly with oxygen, but is present at extremely low concentrations at wine $\mathrm{pH}$. Direct reaction of bisulphite with oxygen is slow, and the antioxidant activity lies in the ability to reduce the $\mathrm{H}_{2} \mathrm{O}_{2}$ to water, convert $o$-quinones back to $o$-diphenols and react directly with $o$-quinones to form sulphonic acids (Danilewicz, 2007).

A number of carbonyl compounds (mainly acetaldehyde, pyruvic acid and $\alpha$-keto-glutaric acid) can bind with free $\mathrm{SO}_{2}$ individually to form complex compounds (Jackowetz \& De Orduña, 2013). The bisulphite-acetaldehyde addition product normally accounts for the majority of the bound $\mathrm{SO}_{2}$ in wine. Reactions with carbonyl compounds such as acetaldehyde lead to the formation of bisulphite addition products in reversible reactions; however, other reactions, such as those between bisulphite and $o$-quinones, form stable adducts and are irreversible (Laurie et al., 2012). Nevertheless, there is a general trend in the wine industry towards minimising $\mathrm{SO}_{2}$ content, and the use of appropriate substitutes and supplements is a popular topic in research. To date, no single replacement for $\mathrm{SO}_{2}$ has been found that combines antimicrobial and antioxidant characteristics.

Glutathione is a sulphur-containing tripeptide (L- $\gamma$ glutamyl-L-cysteinyl-glycine) and a naturally occurring antioxidant from the grapes and yeast metabolism. The concentration in the must is influenced by the nitrogen uptake of the vine (Chone et al., 2006) and it is accumulated in the berry at the onset of véraison (Adams \& Liyanage, 1993). Concentrations of GSH in 28 young Sauvignon blanc wines averaged at $12.5 \mathrm{mg} / \mathrm{L}$ (Janeš et al., 2010), and winemaking conditions promoting oxygen exposure led to a decrease in GSH concentrations, while higher concentrations have been observed in juices treated reductively (Du Toit et al., 2007; Maggu et al., 2007).

GSH has an electron-rich nucleophilic mercapto group that can be substituted spontaneously by 1,4-Michael addition to the electrophilic centre of the $o$-quinone formed during oxidation. The product is a thioether, 2-S-glutathionylcaftaric acid or grape reaction product (GRP). The formation of GRP traps the $o$-quinone, thus preventing any further reactions taking place (Kritzinger et al., 2013a). Glutathione can also react with oxygen species such as $\mathrm{H}_{2} \mathrm{O}_{2}$ (Anderson, 1998) to be oxidised to glutathione disulphide. It has been argued that the disulphide can also be formed by reducing the $o$-quinone back to the $o$-diphenol (Cilliers \& Singleton, 1990). This may explain increasing trans-caftaric and coutaric acid concentrations in must after GSH additions, as reported by Penna et al. (2001).

Glutathione is also capable of carrying out nucleophilic reactions with other compounds such as aldehydes (Cheynier et al., 1986; Cheynier \& Van Hulst, 1988; Sonni et al., 2011) and has protective abilities toward important aroma compounds such as esters, monoterpenes and volatile 
thiols (Papadopoulou \& Roussis, 2001; Lavigne-Cruège \& Dubourdieu, 2003; Roussis et al., 2007; Papadopoulou \& Roussis, 2008). However, GSH has also been shown to induce the production of $\mathrm{H}_{2} \mathrm{~S}$ during wine ageing under lowoxygen conditions (Ugliano et al., 2011).

Glutathione has been linked to the aroma potential of Sauvignon blanc grapes due to the identification of glutathionylated precursors for 3MH and 4MMP (Peyrot des Ganchos et al., 2002). The addition of GSH to must or wine is not legally permitted. However, yeast extracts (which contain GSH) are claimed to preserve the freshness and increase the mouthfeel, as well as the aromatic complexity, of white wines (Kritzinger et al., 2013b). These extracts are available commercially.

Ascorbic acid has been considered as a potential replacement for sulphur dioxide due to its ability to scavenge oxygen (Bauernfeind \& Pinkert, 1970). The reaction of ascorbic acid with oxygen produces dehydroascorbic acid as well as $\mathrm{H}_{2} \mathrm{O}_{2}$. It thus is important to have sufficient $\mathrm{SO}_{2}$ present to react with the formed $\mathrm{H}_{2} \mathrm{O}_{2}$ in order to prevent further oxidation reactions from taking place (Peng et al., 1998).

Ascorbic acid initially functions as an antioxidant; however, over time, the presence of ascorbic acid can lead to enhanced $\mathrm{SO}_{2}$ consumption and oxidation of phenolic compounds, resulting in browning (Peng et al., 1998; Bradshaw et al., 2001; 2003; 2004; Clark et al., 2008). However, the addition of ascorbic acid to Chardonnay wines at bottling resulted in wines being less oxidised and/or having more fresh fruity aromas compared to wines bottled without ascorbic acid (Skouroumounis et al., 2005b).

\section{Effect of oxygen on white wine colour}

The colour of white wine is one of the important quality parameters. Dark yellow or brown colour usually indicates the oxidation or spoilage of white wine. A positive correlation between total phenolic content and browning has been reported (Simpson, 1982). However the content of hydroxycinnamic acids in the wines correlated poorly with browning (Fernandez-Zurbano et al., 1995). The hydroxycinnamic acids may, however, contribute to the browning through coupled oxidation reactions (Simpson, 1982; Fernandez-Zurbano et al., 1995). The monomeric flavan-3-ols and dimeric procyanidins play an important role in white wine colouration, with (-)-epicatechin correlating more strongly with the brown colour when compared to $(+)$-catechin (Simpson, 1982). Browning in white wine can be due to different mechanisms. Firstly, the oxidation of phenolic molecules to their corresponding $o$-quinones leads to further reactions with phenolic compounds to produce dimers, which appear to be more susceptible to oxidation, and thus accelerate phenol polymerisation and autocatalytic oxidation in wine (Singleton, 1987). The formation of these polymers can result in the formation of more intensely coloured yellow-brown compounds (Es-Safi et al., 1999).

The second mechanism is the oxidative degradation of tartaric acid leading to the formation of glyoxylic acid, which can mediate condensation reactions of flavan-3-ols, potentially contributing to browning in white wines.
SAUVIGNON BLANC AROMA AND EVOLUTION DURING AGEING AND OXIDATION

Vitis vinifera L. cv. Sauvignon blanc is a grape variety native to Bordeaux (Graves) and the Loire Valley (Sancerre and Pouilly Fumé) (Adams \& Liyanage, 1993). This variety is now widely cultivated in many other wine-growing regions across the globe, including South Africa, Australia, New Zealand, Chile and the United States (Jackson, 2008). The grapes ripen to moderate to high levels of acidity, producing fresh, crisp and dry white wines with pungent aroma and flavour (Cooper, 2008). Generally, South African Sauvignon blanc wines are cold-fermented in stainless steel tanks and not exposed to oak. In this way, the terroir (often delivering fresh and fruity aromas) is reflected in the wine.

Depending on the climate, Sauvignon blanc wines can offer a range of wine styles. On the one hand, the wine can deliver fresh and fruity characters reminiscent of "guava", "grapefruit", "gooseberries" and "passion fruit", which usually originate from grapes grown in a warmer climate. On the other hand, the more "green" style Sauvignon blanc can be produced from cooler grape-growing regions delivering aroma nuances such as "green pepper", "grassy" and "asparagus" (Lund et al., 2009b). The aroma of Sauvignon blanc is known to change dramatically over a period of just a year in the bottle, meaning that the wine should be drunk early to experience the intended aromatic bouquet of the wine (Herbst, 2010).

Various chemical compounds contribute to the aromatic composition of a wine. Sauvignon blanc impact compounds, such as the volatile thiols and the methoxypyrazines, can contribute significantly to the typical character of the wine. Other aroma groups, such as ester, alcohols, acids and monoterpenes, can also contribute to the pleasant wine aroma. Wines developing a 'reductive' aroma will typically have negative aroma descriptors due to low oxygen exposure, while various oxidation-related compounds such as aldehydes, lactones and acetals will contribute to an unpleasant aroma. In the following sections, details are provided of the most important aroma-contributing groups.

\section{Volatile thiols}

Thiols (more traditionally referred to as mercaptans) are sulphur-containing compounds possessing a sulfhydryl group (-SH). Various sulphur-containing compounds occur in wine and can contribute to a range of aromatic nuances, depending on the type of compound. Certain thiols typically contribute to the fruity characters of a wine, and attributes such as "grapefruit", "passion fruit", "box tree" and "gooseberry" have been used to describe the odour (Darriet et al., 1995; Tominaga et al., 1998a). These compounds are referred to as the volatile thiols.

Other sulphur-containing compounds can contribute to a 'reductive' aroma due to the low oxygen content in certain wines, and the aroma reminiscent of "rotten egg", "garlic" and "cabbage" occurs (Rauhut, 1993; Brajkovich et al., 2005). Compounds such as furfural and 5-hydroxymethylfurfural (5-HMF) (also sulphur-containing compounds) can also impart significant aroma to a wine.

Although first identified in Sauvignon blanc wine during the 1990s, the presence of volatile thiols has also 
been reported in wines made from other varieties (both red and white), such as Riesling, Colombard, Semillon, Cabernet Sauvignon and Merlot (Bouchilloux et al., 1998; Tominaga et al., 2000; Murat et al., 2001b). Along with methoxypyrazines, volatile thiols are considered to be impact odorants for Sauvignon blanc wines due to the fact that they form part of the typicality of the variety and are highly sought after by consumers (Goniak \& Noble, 1987; Rauhut, 1993; Tominaga et al., 2004; Lund et al., 2009b; King et al., 2011). The volatile thiols playing an important role in Sauvignon blanc wine aroma are mainly 4-mercapto4-methylpentan-2-one (4MMP), 3-mercaptohexan-1-ol (3MH) and 3-mercaptohexan-1-ol acetate (3MHA) (Darriet et al., 1995; Tominaga et al., 1996; 2000; 2004; Coetzee \& Du Toit, 2012). Other volatile thiols have been identified; however, the concentration of these compounds in wines is usually below the perception threshold (Tominaga et al., 1998a).

3MHA has been described as "sweet-sweaty passion fruit", "grapefruit", "box tree", "gooseberry" and "guava" (Tominaga et al., 1996; Nicolau et al., 2006) and has a very low perception threshold of $4.2 \mathrm{ng} / \mathrm{L}$ in a model wine solution (Tominaga et al., 1996). 3MH has been described as "passion fruit", "grapefruit", "gooseberry" and "guava" (Swiegers et al., 2005; Nicolau et al., 2006; Van Wyngaard et al., 2014), with a perception threshold of $60 \mathrm{ng} / \mathrm{L}$ (Tominaga et al., 1998a), while 4MMP has been described as "box tree", "passion fruit", "broom" and "black current bud" (Darriet et al., 1995), with a perception threshold of $0.8 \mathrm{ng} / \mathrm{L}$ in a model wine solution (Tominaga et al., 1998a). The low perception thresholds reported makes these compounds potent aromatic contributors in wine.

In a study done on 24 South African Sauvignon blanc wines (2011 vintage), the average thiol concentrations were found to be $10 \mathrm{ng} / \mathrm{L}, 158 \mathrm{ng} / \mathrm{L}$ and $969 \mathrm{ng} / \mathrm{L}$ for 4MMP, 3MHA and 3MH respectively (Van Wyngaard, 2013). These concentrations were in line with those found in other studies investigating Sauvignon blanc wines from all over the world, including New Zealand, Australia, France and Chile (Benkwitz et al., 2012b), with the exception of 3MH, for which the concentrations were lower (Lund et al., 2009b; Benkwitz et al., 2012b).

Unlike the methoxypyrazines, which are present as such in the grapes, the volatile thiols (4MMP and $3 \mathrm{MH}$ ) are thought to be released in part by the yeast from odourless, non-volatile precursors during fermentation (Darriet et al., 1995; Tominaga et al., 1996). Some precursors in the juice have been identified as being cysteinylated or glutathionylated precursors (Tominaga et al., 1998b; Peyrot des Ganchos et al., 2002; Fedrizzi et al., 2009). However, studies have shown that these precursors account for only a fraction of the total amount of thiols present in the wine (Subileau et al., 2008a; Roland et al., 2010a; 2010b), and no direct correlation between precursor concentration and the amount of free volatile thiols in the resulting wines has been observed (Capone et al., 2010; Roland et al., 2011; Pinu et al., 2012). Other than release from precursors, the biogenesis of volatile thiols also has been proposed. The direct addition of $\mathrm{H}_{2} \mathrm{~S}$ or another sulphur donor to conjugated carbonyl compounds such as (E)-2-hexenal and mesityl oxide, followed by a reduction step, has been shown to contribute significantly to the pool of volatile thiols in Sauvignon blanc wines (Harsch et al., 2013). The formation of the volatile thiols is not fully understood, since the main precursor has yet to be elucidated and the production of these volatile thiols needs further investigation.

3MHA is formed by the esterification of $3 \mathrm{MH}$ with acetic acid during fermentation. The final concentration of 3MHA (and other fermentative esters) depends on the balance of activities of alcohol acetyltransferase (promoting estrification of the corresponding alcohol) and esterase (promoting hydrolysis). Yeast strains differ in their ability to release the volatile thiols from their precursors, and also in their ability to convert 3MH to 3MHA (Murat et al., 2001a; Swiegers et al., 2005; 2006; Anfang et al., 2009). 3MHA typically amounts to $10 \%$ of the concentration of $3 \mathrm{MH}$ (Tominaga et al., 2000; Dubourdieu et al., 2006).

The formation of volatile thiols can be manipulated through both viticultural and oenological operations. Research on the impact of viticultural practices on the production of volatile thiol precursors is limited and under question, due to the main mechanisms of volatile thiol formation from precursors not yet being identified. The effect of factors such as nitrogen fertilisation, water availability and Botrytis cinerea infection on certain precursors has been reported (Choné, 2001; Peyrot des Ganchos et al., 2005; Choné et al., 2006; Sarrazin et al., 2007; Thibon et al., 2009). During winemaking, various processes can also be adapted to maximise precursor extraction and/or formation, as well the liberation of the thiol from the precursor. Practices such as mechanical harvesting, skin contact, pressure during pressing and oxygen exposure could significantly increase the precursor content in the juice and influence the volatile thiol concentration in the corresponding wines (Maggu et al., 2007; Patel et al., 2010; Roland et al., 2010b; Capone \& Jeffery, 2011). The liberation of the volatile thiols from the respective precursors depends on conditions such as yeast strain, nitrogen availability and fermentation temperature (Murat et al., 2001a; Masneuf-Pomarède et al., 2006; Swiegers et al., 2006; Subileau et al., 2008b; Anfang et al., 2009; Harsch et al., 2013). More detail regarding the influence of these processes on the volatile thiol concentrations can be obtained from a review article published in 2012 (Coetzee \& Du Toit, 2012).

The volatile thiols are particularly susceptible to oxidation during ageing (Murat et al., 2003; Blanchard et al., 2004), and various packaging and ageing studies have reported the decrease of the volatile thiols during storage (Murat, 2005; Lopes et al., 2009; Herbst-Johnstone et al., 2011; Ghidossi et al., 2012). The volatile thiols $3 \mathrm{MH}$ and 3MHA were also found to mainly decrease in Sauvignon blanc wines that were exposed to repetitive oxidation (Coetzee, 2014). Three mechanisms have been identified through which the thiol content can decrease. Volatile thiols can oxidise easily in the presence of oxygen and iron to form the corresponding disulphides (Jocelyn, 1972; Kotseridis et al., 2000). Furthermore, these thiols are nucleophilic and capable of addition reactions with electrophiles such as polymeric phenolic compounds (Ribéreau-Gayon et al., 2006), and participate in chemical reactions (1,4-Michael- 
type addition) with the products of phenolic oxidation such as o-quinones (Herbst et al., 2008; Nikolantonaki et al., 2010). The formed adducts are non-volatile and would cause a loss in varietal character. Recent observations have reported $o$-quinone trapping as the main mechanism accounting for $3 \mathrm{MH}$ loss in wine under oxidative conditions, while other reactions seems to contribute marginally (Kreitman et al., 2013).

The rate of these reactions are $\mathrm{pH}$ dependent, since the concentration of the thiolate ion (RS), which is more reactive than its protonated form $(\mathrm{RSH})$, is low at wine $\mathrm{pH}$, with $\mathrm{pK}_{\mathrm{a}}$ values for thiols typically being between 9 and 12 . The greater proportion of thiolate anions at higher $\mathrm{pH}$ may explain the consistently lower levels of $3 \mathrm{MH}$ under these conditions (Blanchard et al., 2004).

The decrease in especially 3MHA can also be attributed to acid-catalysed hydrolysis at wine $\mathrm{pH}$ (Tominaga et al., 2004). The ester structure of 3 MHA makes it susceptible to this type of reaction. Volatile acetate esters are introduced enzymatically to the wine during fermentation by the action of yeast via a combination of acetyl-CoA with an alcohol, which is catalysed by alcohol acetyltransferase. The products of this reaction are $3 \mathrm{MH}$ and acetic acid. The hydrolysis reaction is expected to be accelerated by higher temperature, but not directly affected by oxidative conditions (Makhotkina \& Kilmartin, 2012).

Acid hydrolysis was found to have a stronger influence than $o$-quinone trapping on the decrease in 3MHA concentrations during bottle ageing of Sauvignon blanc wine under highly hermetic conditions such as screw caps (Herbst et al., 2008; Herbst-Johnstone et al., 2011). As 3MH has a higher perception threshold than 3MHA, the hydrolysis is expected to result in lower aromatic intensity and possibly a different aroma.

The presence of $\mathrm{SO}_{2}$ was shown to prevent the loss of volatile thiols due to its ability to recycle the $o$-quinones to the original phenol, bind them directly, or reduce $\mathrm{H}_{2} \mathrm{O}_{2}$ to water (Danilewicz et al., 2008; Nikolantonaki et al., 2010; Laurie et al., 2012). However, the formation of the $o$-quinone adducts was shown to occur even in the presence of $\mathrm{SO}_{2}$, although to a lower extent (Nikolantonaki et al., 2012).

\section{Methoxypyrazines}

Methoxypyrazines are secondary plant metabolites with nitrogen-containing ring structures that are responsible for aroma descriptors such as "green pepper", "asparagus", "grassy", "herbaceous" and "vegetative". Three main methoxypyrazines occur in wines, namely 3-isobutyl-2methoxypyrazine (IBMP), 3-isopropyl-2-methoxypyrazine and 3-sec-butyl-2-methoxypyrazine (Allen et al., 1991; Lacey et al., 1991; Marais, 1994).

These compounds have a very low odour threshold value of 1 to $2 \mathrm{ng} / \mathrm{L}$ in water (Buttery et al., 1969; Allen et al., 1991; Lacey et al., 1991; Marais, 1994), and surveys done on South African Sauvignon blanc wines reported the IBMP (the most important methoxypyrazine) concentrations to be in the range of 1.2 to $40 \mathrm{ng} / \mathrm{L}$ (Alberts et al., 2009; Van Wyngaard, 2013).

Settling of the juice before fermentation can lead to a decrease in methoxypyrazine concentrations (Kotseridis et al., 2008), while concentrations have been reported to remain stable during fermentation (Sala et al., 2004). The compounds are generally resilient to standard wine fining practices (Pickering et al., 2006), and concentrations did not differ when exposed to various ageing conditions, such as light exposure and temperature variations (Blake et al., 2010). Even hyperoxidation of the musts and wine did not alter the methoxypyrazine content (Marais, 1998; Coetzee et al., 2013). Surprisingly, a weak correlation $\left(\mathrm{r}^{2}=0.37\right)$ was obtained when comparing IBMP concentration with the aromatic intensity of the "capsicum" attribute (Lund et al., 2009 b). The contribution of other aromatic compounds, such as the varietal thiols, C6-alcohols and dimethyl sulphide, to these types of attributes can be significant in Sauvignon blanc wines and help explain the weak correlation observed previously (Park et al., 1994; Marais et al., 1998; Lund et al., 2009b; Kotseridis et al., 2000; King et al., 2011; Van Wyngaard, 2013; Coetzee et al., 2015a).

\section{Esters, higher alcohols, fatty acids}

Esters constitute one of the most important classes of aroma compounds and are largely responsible for the fruity aromas associated with wine (Lilly et al., 2000; Swiegers et al., 2006). Esters are mainly produced during fermentation through the condensation of an alcohol and a coenzymeA-activated acid by the action of alcohol acetyl transferase (Lambrechts \& Pretorius, 2000). A large variety of esters can be formed, as all of the alcohols (especially ethanol) and fatty acids may react to form esters. Acetate esters of the higher alcohols and the ethyl esters of straight-chain saturated fatty acids are the most significant esters produced in wine (Lambrechts \& Pretorius, 2000). Some of the most quantitatively significant esters in wine have been identified to be isoamyl acetate, ethyl hexanoate and 2-phenylethyl acetate (Thurston et al., 1981).

Ester concentration can decrease during ageing due to chemical hydrolysis (Marais, 1978; Ferreira et al., 1997; Lambropoulos \& Roussis, 2007) or oxidation due to direct attack by hydroxyl radicals or by ester interaction with o-quinones (Escudero et al., 2000a; Patrianakou \& et al., 2013), which can lead to a loss of the fruity character of a wine. The hydrolysis is favoured at elevated temperatures and low $\mathrm{pH}$ values (Ramey \& Ough, 1980). The decline in the acetate esters in particular contributes to the loss of freshness and fruitiness in white wines during bottle ageing. Acetate esters of higher alcohols tend to diminish more rapidly during ageing compared to ethyl esters of fatty acids. Ethyl esters are thought to be close to their chemical equilibrium in young wines (Simpson, 1978), and the hydrolysis that occurs during storage happens relatively slowly (Ramey \& Ough, 1980).

Higher alcohols are also a product of alcoholic fermentation and can be important precursors for ester formation (Soles et al., 1982). At concentrations below $300 \mathrm{mg} / \mathrm{L}$ they generally contribute to the complexity of the wine aroma (Rapp \& Mandery, 1986). However, at higher concentrations the aroma can become too intense and can contribute to a strong, pungent smell and taste (Nykänen, 1986), thus possibly masking other aroma contributors. Higher alcohols can be anabolically synthesised from 
intermediates of the sugar metabolism or catabolically synthesised from branched-chain amino acids through the Ehrlich pathway (Nykänen, 1986; Boulton et al., 1996; Dickinson et al., 1997; 2003). During ageing, alcohols can be oxidised to form aldehydes (Marais \& Pool, 1980), causing the concentration to decrease. However, many studies report stable alcohol concentrations during the ageing of wines (Marais, 1978; Roussis et al., 2005; 2007; Blake et al., 2009). Unlike other higher alcohols, the concentration of hexanol can increase during storage, which is probably due to the oxidation of linoleic and linolenic acids (Oliveira et al., 2006).

Fatty acids, of which the most abundant are acetic, hexanoic, octanoic and decanoic acid, contribute to the fresh flavour of wine. However, at very high concentrations of fatty acids, unwanted flavours described as "rancid", "cheesy" and "vinegar" can develop (Schreier, 1979; Lambrechts \& Pretorius, 2000). Medium-chain fatty acids, such as hexanoic, octanoic and decanoic acid, are produced by the yeast as intermediates in the biosynthesis of long-chain fatty acids. The hydrolysis of ethyl esters during ageing can lead to an increase in the corresponding acid. However, an increase in these acids has not always been observed, as studies have shown that the stability of volatile fatty acids is not uniform, as some compounds increase while others decrease or remain stable during ageing (Roussis et al., 2005; Câmara et al., 2006; Blake et al., 2009; Lee et al., 2011).

Many factors can influence the formation and degradation of esters, higher alcohols and fatty acids during fermentation, ageing or oxidation. Fermentation conditions such as temperature, juice clarification and yeast strain, as well as other parameters such as oxygen exposure and $\mathrm{SO}_{2}$ additions, are some of the most important factors (Bertrand, 1968; Daudt \& Ough, 1973; Marais, 2001; Garde-Cerdán \& Ancín-Azpilicueta, 2007; Coetzee et al., 2013).

\section{Monoterpenes}

Monoterpenes are known for their "floral", "fruity", "citrus" and "perfume" odours, usually expressed by geraniol, linalool, nerol and $\alpha$-terpineol (Marais, 1983). Sauvignon blanc can be classified as a member of an intermediate class between monoterpene-dependent floral grapes and monoterpene-deficient non-floral grapes (Benkwitz et al., 2012a). Most terpenes increase during ripening (Bayonove \& Cordonnier, 1971), with some studies reporting a decrease at the overripe stage (Versini et al., 1981). A considerable proportion of these compounds are in the bound form in the juice and are released during fermentation by the yeast; however, some can become aromatic by chemical rearrangement such as the non-enzymatic rearrangement of hydroxylated linalool derivatives to give several volatile terpenes, including $\alpha$-terpineol (Williams et al., 1980; Loscos et al., 2007). The oxidation mechanism is known to play a role in some cases in the release and rearrangement of the terpenes (Williams et al., 1982; Marais, 1983).

During ageing, wines are known to lose some of the floral aromas associated with monoterpenes (Rapp \& Mandery, 1986; Rapp, 1988). Linalool specifically is known to decrease during storage (Ferreira et al., 1997; Lambropoulos \& Roussis, 2007), while $\alpha$-terpineol initially increased (probably due to the oxidation of other terpenols) and then decreased at a later stage (Ferreira et al., 1997). Terpenes are sensitive to acidic conditions, storage time and temperature and can be transformed into other compounds, which could contribute to a different aroma and have different perception thresholds (Papadopoulou \& Roussis, 2001; Roussis et al., 2005; 2007). The importance of monoterpenes in wines is accentuated by the fact that these compounds act synergistically in a wine medium and thus can influence the aromatic composition of a wine (RibéreauGayon et al., 1975).

\section{REDUCTIVE AROMA}

'Reductive' aroma properties have been described as "rotten egg", "cabbage" and "garlic". The compounds responsible for these aroma attributes usually form after a period in the bottle. The occurrence of these odours has been attributed to the presence of low molecular weight sulphur compounds. Hydrogen sulphide $\left(\mathrm{H}_{2} \mathrm{~S}\right)$ and methyl mercaptan $(\mathrm{MeSH})$ have been identified as being primarily responsible for postbottling reduction (Lopes et al., 2009; O'Brien et al., 2009; Ugliano et al., 2011; 2012). $\mathrm{H}_{2} \mathrm{~S}$ can accumulate during bottle ageing, and concentrations three to four times higher than its perception threshold have been reported after six months in the bottle (Ugliano et al., 2011).

The mechanisms for the formation of the 'reductive' compounds are not fully understood. However, the formation of $\mathrm{H}_{2} \mathrm{~S}$ from a cysteine precursor in the presence of a dicarbonyl compound and the direct reduction of sulphate or sulphite have been suggested (Pripis-Nicolau et al., 2000; Lopes et al., 2009). Interestingly, studies have shown an increase in the formation of 'reductive' odours in wines that were treated with copper sulphite at bottling, which is a common practice amongst winemakers to prevent the formation of these odours (Ugliano et al., 2011). The addition of glutathione to Sauvignon blanc wine also led to increased levels of $\mathrm{H}_{2} \mathrm{~S}$, although the preservation effect of GSH addition on $3 \mathrm{MH}$ concentrations was more favourable (Ugliano et al., 2011).

$\mathrm{H}_{2} \mathrm{~S}$ also can participate in other reactions, such as the reaction with benzaldehyde to form methyl mercaptan, which can contribute to a 'reductive' aroma in the wine, with "smoky/empyreumatic", "cabbage" and "sewage" nuances. However, this has not been demonstrated conclusively (Tominaga, 2003; Tominaga et al., 2003; Ugliano, 2013).

Keeping oxygen levels low during bottle ageing led to a larger accumulation of $\mathrm{H}_{2} \mathrm{~S}$ and $\mathrm{MeSH}$ (Lopes et al., 2009; Ugliano et al., 2011; 2012), with the accumulation of MeSH occurring mainly in the first six to 12 months of bottle storage (Ugliano et al., 2012). Dimethyl sulphide (DMS) also increases during bottle ageing and can make an important contribution to wine aroma (Segurel et al., 2005; Escudero et al., 2007). The formation of DMS does not seem to be affected by oxygen exposure (Ugliano et al., 2012), although a decrease in DMS has been reported in the presence of excess oxygen (Silva Ferreira et al., 2003c; Fedrizzi et al., 2011). Oxygen exposure also will lead to a decrease in $\mathrm{H}_{2} \mathrm{~S}$ and $\mathrm{MeSH}$ concentrations. The oxidation of mercaptans to the corresponding disulphides has been proposed, but not proven (Limmer, 2005), and 
recent data have not found a direct relationship between the mercaptan and the disulphides (Nguyen et al., 2010; Ugliano et al., 2012). The reaction of 'reductive' compounds with $o$-quinones resulting from phenolic oxidation could explain the decrease of especially $\mathrm{H}_{2} \mathrm{~S}$ and $\mathrm{MeSH}$ in an oxygenated wine due to the high reactivity of $\mathrm{H}_{2} \mathrm{~S}$ toward $\mathrm{o}$-quinones in wine-like solutions (Nikolantonaki \& Waterhouse, 2012). The presence of oxygen during the early stages of bottle ageing thus will prevent the formation of these compounds, possibly at a precursor level. However, this needs further investigation (Ugliano, 2013).

\section{OXIDATION AROMA}

Early work on the oxidative spoilage of white wines indicated that oxidation brought about sensory characters described as "honey", "farmfeed", "woody" and "cooked vegetables" (Escudero et al., 2002; Silva Ferreira et al., 2003b). A number of trace aroma compounds have been identified as major contributors to these aroma attributes, including various aldehydes, lactones and acetals (Escudero et al., 2000a; 2000b; 2002; Silva Ferreira et al., 2002b; 2003 b). The aldehydes are especially important because of their possible impact on wine aromatic composition (Escudero et al., 2000b; Silva Ferreira et al., 2003b; Culleré et al., 2007). The various chemical compounds potentially contributing to wine oxidation aromas will be discussed in the following sections.

\section{Aldehydes}

Acetaldehyde is one of the most important carbonyl compounds in wine and constitutes up to $90 \%$ of the total amount of aldehydes found in wine (Nykänen, 1986). Its organoleptic influence and its ability to combine rapidly with $\mathrm{SO}_{2}$, even at low temperatures, makes this compound one of the critical markers during winemaking (Burroughs \& Sparks, 1973). Acetaldehyde in the free form is a key impact aroma compound for sherry wines, and can reach high concentrations in these types of wines (Martínez et al., 1998). Odours associated with the presence of free acetaldehyde have been described as "green apple", "overripe bruised apple", "grassy", "pungent", "nutty" and "sherry" (Margalith, 1981; Henschke \& Jiranek, 1993; Miyake \& Shibamoto, 1993; Frivik \& Ebeler, 2003).

Acetaldehyde is formed by the yeast during alcoholic fermentation (Margalit, 1997) and can also originate from the microbial activity of other microbes, such as lactic acid bacteria and acetic acid bacteria (Drysdale \& Fleet, 1988; Liu \& Pilone, 2000). However, winemaking practices that enhance acetaldehyde formation are usually post-fermentation, and can lead to moderate to important acetaldehyde increases (Jackowetz \& De Orduña, 2013).

The most important production of acetaldehyde is during the oxidation of ethanol (Wilderandt \& Singleton, 1974; Ribéreau-Gayon, et al., 2006). This reaction is not direct, but rather via the coupled auto-oxidation of certain phenolic compounds (Fig. 2) (Wilderandt \& Singleton, 1974), and the formation will depend on the amount of oxygen present (Kielhöfer \& Würdig, 1960; Schneider, 2003; 2005).

Acetaldehyde concentration (free and bound) in dry white wines has been reported to range between 7 and 240 $\mathrm{mg} / \mathrm{L}$, averaging at $40 \mathrm{mg} / \mathrm{L}$ (Lopes et al., 2009; Jackowetz $\&$ De Orduña, 2013), while the highest concentrations were reported in fortified wines ranging from 12 to $800 \mathrm{mg} / \mathrm{L}$ (Lachenmeier \& Sohnuis, 2008). Coetzee (2014) found levels to increase gradually, reaching up to $100 \mathrm{mg} / \mathrm{L}$ total acetaldehyde in a Sauvignon blanc wine exposed to repetitive oxidation.

Other aldehydes can contribute to "honey", "boiled vegetable" and "rotten potato" nuances in oxidised wines (Escudero et al., 2000b; Culleré et al., 2007). Of these aldehydes, the Strecker aldehydes, 3-(methylthio)propionaldehyde (methional) and phenylacetaldehyde, have been identified as major contributors (Escudero et al., 2000a; 2000b; 2002; Silva Ferreira et al., 2002b; 2003b). The formation of these aldehydes has been proposed to occur via the Strecker reaction of dicarbonyl compounds with amino acids, methionine and phenylalanine to form methional and phenylacetaldehyde respectively (Fig. 3) (Escudero et al., 2000b; Pripis-Nicolau et al., 2000; Silva Ferreira et al., 2002b; Rizzi, 2006).

The formation of aldehydes from the oxidation of related fermentation-derived alcohols (phenylethanol and methionol) has also been suggested (Escudero et al., 2000a; 2000b; Pripis-Nicolau et al., 2000; Silva Ferreira et al., 2002b; Rizzi, 2006; Loscos et al., 2010; Fedrizzi et al., 2011; Nikolantonaki \& Waterhouse, 2012). Methional and phenylacetaldehyde have perception thresholds of $0.5 \mu \mathrm{g} / \mathrm{L}$ and $1 \mu \mathrm{g} / \mathrm{L}$ in a synthetic wine medium respectively (Escudero et al., 2000b; Culleré et al., 2007), and concentrations in a young Sauvignon blanc wine just after bottling were found to be below 0.5 and $5 \mu \mathrm{g} / \mathrm{L}$ respectively. After 18 months ageing at $20^{\circ} \mathrm{C}$, the concentrations increased to about 5.5 and $34 \mu \mathrm{g} / \mathrm{L}$ respectively (Ghidossi et al., 2012). Higher concentrations of these compounds in various white wines have been reported in more extreme storage conditions, such as higher dissolved oxygen concentrations and higher storage temperatures (Silva Ferreira et al., 2003b).

The formation of methional and phenylacetaldehyde are greatly affected by temperature and by the concentration of dissolved oxygen (Silva Ferreira et al., 2002b). However, both factors are not required for the formation of the aldehydes, as it was found in beer that the aldehydes formed in the absence of oxygen $(<0.2 \mathrm{mg} / \mathrm{L})$ (Soares da Costa et al., 2004). The oxidation of the alcohols, as well as the Strecker degradation reaction, will be prevented by the presence of $\mathrm{SO}_{2}$ (Silva Ferreira et al., 2003b), probably due to its ability to reduce $\mathrm{H}_{2} \mathrm{O}_{2}$ to water, convert the $o$-quinone back to the $o$-diphenol and also reversibly reacting with the microbialderived dicarbonyls. Thus, $\mathrm{SO}_{2}$ should effectively be able to prevent the formation of these aldehydes.

Furfural and other furanic aldehydes, such as 5-methylfurfural (5-MF) and 5-hydroxymethylfurfural (5-HMF), usually originate from the heating process of oak during barrel toasting (Moutounet et al., 1989). The thermal degradation of polysaccharides produces these furanic aldehydes from carbohydrate polymers. The formation of furfural due to the non-oxidative decay of ascorbic acid has also been reported (Bauernfeind \& Pinkert, 1970; Yuan \& Chen, 1998; Wallington et al., 2013). A good correlation between ageing time and the concentration of these furanic 


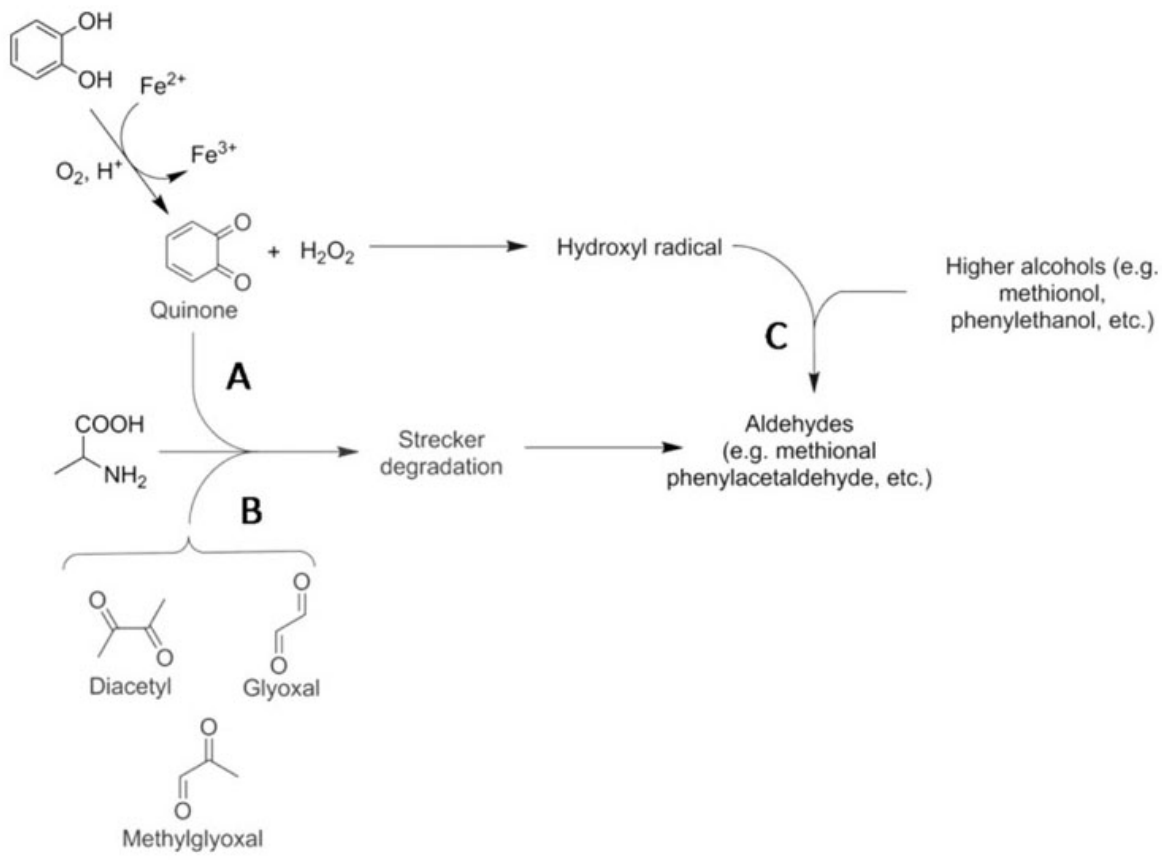

FIGURE 3

Mechanism of formation of branched-chain aldehydes in wines via (A) Strecker degradation of amino acids involving $o$-quinones derived from phenolic oxidation, (B) Strecker degradation involving dicarbonyl compounds of microbial origin, and (C) oxidation of higher alcohols by hydroxyl radical. Reprinted with permission from Ugliano (2013). Copyright American

Chemical Society, 2013.

compounds was found in Port and Madeira wines (Silva Ferreira et al., 2003a; Câmara et al., 2004), and a significant increase is observed in Sauvignon blanc wines aged without oxygen, and even more so in Sauvignon blanc wine to which oxygen was administered at bottling (Coetzee, 2014). The concentrations of furfural and 5-MF in a range of white wines oxidised for one week were found to be between 16 and $342 \mu \mathrm{g} / \mathrm{L}$ and 10 and $60 \mu \mathrm{g} / \mathrm{L}$ respectively (Escudero et al., 2002). Perception thresholds of $150 \mathrm{mg} / \mathrm{L}, 20 \mathrm{mg} / \mathrm{L}$ and $100 \mathrm{mg} / \mathrm{L}$ have been reported for furfural, 5-MF and 5-HMF respectively (Meilgaard, 1975; Câmara et al., 2004), which would suggest minor organoleptic contribution due to the concentrations being below the perception threshold (Ribéreau-Gayon et al., 2006). However, the contribution of these compounds to "woody" or "maderized" nuances during the oxidation of white wines has been reported and could explain the perception of these odours in wines that did not receive any wood contact (Escudero et al., 2002; Campo et al., 2008).

Benzaldehyde is always present in wine and is produced by alcoholic fermentation in concentrations up to $0.5 \mathrm{mg} / \mathrm{L}$. During wine ageing, benzaldehyde formation has been attributed to phenylalanine oxidation (Loyaux et al., 1981), while other authors have reported its origin from amygdalin (Nykänen \& Suomalainen, 1982). The concentration of benzaldehyde in a range of white wines oxidised for one week was found to be between 20 and $313 \mu \mathrm{g} / \mathrm{L}$ (Escudero et al., 2002), and the compound correlated well with the term "liquor" (Escudero et al., 2002). The odour detection threshold for benzaldehyde is $0.35 \mathrm{mg} / \mathrm{L}$ in water (Belitz et al., 2009).

\section{Other carbonyl compounds and acetals}

Sotolon is a chiral furanone (lactone) and a very powerful odorant that has been described to have the odour of "curry" and "myrrh" at high concentrations, with "roasting", "maple syrup", "burnt sugar" and "caramel" at lower concentrations (Escudero et al., 2000a; Ghidossi et al., 2012). Sotolon has been demonstrated to be a key odorant in sherry, port, "vin jaune", and botrytised and "Tokai wines" (Masuda et al., 1984; Martin \& Etiévant, 1991; Guichard et al., 1992; Martin et al., 1992; Silva Ferreira et al., 2003a; Collin et al., 2012), but can have a detrimental effect when present in dry white wines (Escudero et al., 2002; Silva Ferreira et al., 2003b; Lavigne et al., 2008).

The mechanism for the formation of this compound is still not fully understood, although a few pathways have been suggested and the connection between oxidation and sotolon formation seems to be evident (Pham et al., 1995; Cutzach et al., 1999; Silva Ferreira et al., 2003a; 2003c; Escudero et al., 2011). The formation of sotolon can occur via the enzymatic or chemical deamination of threonine, followed by aldol condensation with acetaldehyde in various wine media (Takahashi et al., 1976; Pham et al., 1995; Cutzach et al., 1998). Sotolon can also be formed from the oxidative degradation of ascorbic acid in the presence of ethanol (König et al., 1999; Pons et al., 2010). This mechanism is most likely to occur in dry white wines, especially considering the common practice of adding ascorbic acid to Sauvignon blanc must/wine during winemaking.

The concentrations of this compound in dry white wines are much less compared to other alcoholic beverages (fortified wine, port, sherry) (Salmon et al., 1999). Concentrations in 
young Sauvignon blanc wines just after bottling were found to be below $0.5 \mu \mathrm{g} / \mathrm{L}$, while Sauvignon blanc wine stored under various types of closures during a 24-month period had a sotolon content ranging from 0.1 to $1.1 \mu \mathrm{g} / \mathrm{L}$ (Lopes et al., 2009; Ghidossi et al., 2012). Another study measured concentrations of up to $10 \mu \mathrm{g} / \mathrm{L}$ for Sauvignon blanc wines aged between two and 32 years (Lavigne et al., 2008), while a recent study found concentrations below $0.5 \mu \mathrm{g} / \mathrm{L}$ in a Sauvignon blanc wine to which $30 \mathrm{mg} / \mathrm{L}$ of oxygen was administered during the ageing process (Coetzee, 2014). The formation of this compound in white wines seems to be somewhat dependent on temperature, and a concentration of around $8 \mu \mathrm{g} / \mathrm{L}$ was obtained during a forced aged experiment conducted at $60^{\circ} \mathrm{C}$ (Silva Ferreira et al., 2003b). The odour threshold for this compound has been determined to be $15 \mu \mathrm{g} / \mathrm{L}$ in flor sherry (Martin et al., 1992), $2 \mu \mathrm{g} / \mathrm{L}$ in model wine (Pons et al., 2010) and $8 \mu \mathrm{g} / \mathrm{L}$ in dry white wines (Lavigne et al., 2008).

Acetals are formed by the condensation reaction between glycerol and acetaldehyde in an acid medium. Four isomers can be formed via this reaction: cis- and trans-5-hydroxy-2methyl-1,3-dioxane, and cis- and trans-4-hydroxymethyl-2methyl-1,3-dioxolane. In Port wine, isomers of glycerol and acetaldehyde acetals have been found at total concentrations ranging from 9.4 to $175.3 \mathrm{mg} / \mathrm{L}$ (Silva Ferreira et al., 2002a). During the oxidation of wine, large amounts of the dioxanes and dioxolanes are expected to be produced due to the fact that an ample quantity of substrates is available. Dioxane and dioxolane content in an oxidised Sauvignon blanc wine increased significantly during a seven-month ageing period (Coetzee, 2014).

The aromatic impact of these compounds could contribute significantly to the oxidised odour perceived in some wines as "sweet" and "old port-like" (Silva Ferreira et al., 2002a).

\section{SENSORY SCIENCE}

Evaluating the chemical composition of a wine can deliver valuable information such as the type and quantity of specific aromatic compounds present. However, the use of the chemical composition only is not adequate to predict the aroma profile and wine quality. This is important in a complex medium such as wine, where interactions between all compounds present could influence the sensory perception of the aroma. Sensory analysis (especially descriptive analysis) of wines thus is of critical importance for the evaluation of wine aroma (Stone \& Sidel, 1993; Lawless \& Heymann, 1998). The combination of the chemical and sensory data could deliver valuable information concerning the aroma profile of the wine and how various compounds interact. Descriptive analysis has been used successfully as a tool to differentiate between Sauvignon blanc wines from different vintages and countries (Lund et al., 2009b; Green et al., 2011). These techniques have also been used to investigate interactions between various compounds in Sauvignon blanc wine (King et al., 2011; Benkwitz et al., 2012a; Coetzee et al., 2015a; 2015b), as well as to identify off-flavours in oxidation-spoiled white wines (Silva Ferreira et al., 2003b).

\section{Sensory interaction studies}

Wine is a complex medium containing various types of aroma compounds that can all have an effect (differing degrees of suppression and masking) on each other (Francis \& Newton, 2005). This complicates the investigation of interactive effects between compounds. Over the years, researchers have been trying to understand the interactions of aroma compounds in various media, as different compounds can manifest differently in various media (Maga, 1989; Marais \& Swart, 1999; Campo et al., 2005; Escudero et al., 2007).

Interactive effects between aroma impact compounds that are found especially in Sauvignon blanc wines have been investigated. Combinations containing high concentrations of 4MMP, 3MH and 3MHA not only delivered high intensity ratings for the "cat urine/sweaty" attribute, but also for the "cooked green vegetal" descriptor, thus demonstrating the contribution of the thiols to the 'green' characteristics of a wine (King et al., 2011). Synergism between IBMP and 4MMP has also been reported. When added individually at low concentrations ( $2 \mathrm{ng} / \mathrm{L}$ for IBMP; $0.2 \mathrm{ng} / \mathrm{L}$ for 4MMP), "dusty" was the only attribute generated. However, when added together at the same concentration, the amount of attributes generated by the panel increased to "dusty", "grassy" and "herbaceous" (Marais \& Swart, 1999). When added at higher concentrations, a mutual suppression between the volatile thiols and the methoxypyrazines was observed (Marais \& Swart, 1999; Campo et al., 2005; King et al., 2011; Van Wyngaard et al., 2014). The addition of esters to the base wine increased the perception of the "confectionary" attribute and also increased the ratings of "overall fruit aroma", "tropical" and "cooked green vegetal" attributes (attributes also associated with thiols). Esters are known to be particularly important in the bouquet of young white wines, including Sauvignon blanc, and interact in an additive manner (Van der Merwe \& Van Wyk, 1981; Campo et al., 2005). High thiol concentrations in the presence of an ester combination decreased the ratings for "confectionary", indicating a suppressive effect of the thiols on the esters when present at high levels. In contrast, in the presence of moderate to high thiol concentrations, the esters actually enhanced some thiol-related sensory attributes (Ferreira et al., 2002; Campo et al., 2005; King et al., 2011; Benkwitz et al., 2012a). Overall, the addition of IBMP had a greater impact on the aroma of a wine when compared to the addition of the thiols. The effect of IBMP has been described as being dominant and, in wines containing both thiols and IBMP, the aroma is often driven by IBMP (Hein et al., 2009; King et al., 2011; Van Wyngaard et al., 2014).

Lund et al. (2009a) investigated the interaction of nonvolatile wine compounds, such as polyphenols and volatile aroma compounds, in a diluted wine medium. They found that the perception of IBMP, 3MH and ethyl decanoate was largely suppressed by the addition of polyphenols $((+)$-catechin, quercetin and caffeic acid). On the other hand, the addition of specifically caffeic acid enhanced the perception of $3 \mathrm{MH}$. This could be due to the suppression of other aroma compounds that initially masked the $3 \mathrm{MH}$ aroma (Lund et al., 2009a). The aroma perception of 3MHA was least affected by the polyphenol additions when compared to the other aroma compounds tested in the study. 
The presence of the ester functional group is thought to make it less susceptible to interaction with the polyphenol when compared to the alcohol group of 3MH (Lund et al., 2009a).

Very few studies have investigated the interactive effect of unpleasant aroma compounds, such as compounds related to oxidation. The addition of branched aliphatic aldehydes and (E)-2-alkenals generated attributes such as "sweet orange", "dried fruit", "fusel", "closed room", "dirty", "mouldy" and "rancid", and an additive effect was observed between these aldehydes (Culleré et al., 2007). An in-depth investigation by Coetzee et al. (2015a) on sensory interactions between $3 \mathrm{MH}$, IBMP, methional and phenylacetaldehyde when combined at different levels yielded interesting results. Methional, especially at certain levels, had a strong suppressive effect on the "grapefruit" and "guava" attributes linked to $3 \mathrm{MH}$. Methional and IBMP, however, enhanced the intensity of "cooked potato" and "cooked beans". In a similar study, Coetzee et al. (2015b) found acetaldehyde at lower levels to enhance the fruity aromas associated with $3 \mathrm{MH}$, but suppression occurred at higher levels of acetaldehyde. Higher levels of 3MH might also suppress the "oxidised green apple" often associated with acetaldehyde. Acetaldehyde can also supress the green pepper attribute associated with IBMP. The need to preserve the positive aroma compounds, such as "guava", "passion fruit", etc., while controlling the formation of negative aroma attributes associated with oxidation derived compounds in Sauvignon blanc, thus is of the utmost importance to the wine producer.

The sensory interactive effect of reductive compounds such as $\mathrm{H}_{2} \mathrm{~S}$ could have important implications for Sauvignon blanc wines. Sauvignon blanc wines are often made in a reductive manner, with the aim being to preserve the fruity aroma as much as possible. However, due to the exclusion of oxygen, reductive compounds could contribute negative odours to the wine. The suppressive effect of some of these reductive compounds needs further investigation, seeing that it would exist in the wine medium together with some the typical Sauvignon blanc impact compounds, which should, at this stage, be present in high concentrations.

\section{CONCLUSIONS}

Oxygen management-related issues are estimated to compromise the quality of approximately 3\% of all wines before the bottles reach the retailer (Nygaard, 2010). Consumers are sensitive to wine faults, such as 'reductive' and oxidative aromas, and this will decrease the liking scores and purchase intent (Nygaard, 2010). The management of oxygen during winemaking thus is generating considerable interest in the wine world. If oxygen exposure is too high or too low, wines can develop defects that can compromise their sensory quality. Too little oxygen exposure could lead to a wine with 'reductive' odours, while too much oxygen can result in an oxidised wine displaying other unpleasant aromas, together with a decrease in pleasant fruity aromas. The challenge thus is to identify the right amount of oxygen needed for a specific wine to maintain the perfect balance between chemical composition and sensory perception. Other than that, research focusing on the evolution of the compounds during the oxidative ageing of wines is needed to better understand the relationships between compounds and mechanisms. Such research should also be conducted under the conditions that the wine might encounter in a commercial cellar situation, and not only be performed under conditions of enhanced oxidation.

The complexity of a wine as a medium greatly complicates research attempts. Sauvignon blanc wine, especially, is known for its large diversity of flavours, which adds to the complexity. The volatile thiols and the methoxypyrazines are the main compounds involved in the unique character of Sauvignon blanc wines; however, by themselves these key molecules do not account for the aromatic complexity of high-quality wines. Various interactions occur between both volatile and non-volatile wine constituents, and these interactions can change as the concentrations change. Studies have attempted to identify some of these interactive effects. However, much more research is needed to successfully address this issue.

\section{LITERATURE CITED}

Adams, D.O. \& Liyanage, C., 1993. Glutathione increases in grape berries at the onset of ripening. Am. J. Enol. Vitic. 44, 333-338.

Alberts, P., Stander, M.A., Paul, S.O. \& De Villiers, A., 2009. Survey of 3-alkyl-2-methoxypyrazine content of South African Sauvignon blanc wines using a novel LC-APCI-MS/MS method. J. Agric. Food Chem. 57, 9347-9355.

Allen, M.S., Lacey, M.J., Harris, R.L.N. \& Brown, W.V., 1991. Contribution of methoxypyrazines to Sauvignon blanc wine aroma. Am. J. Enol. Vitic. 42, 109-112.

Anderson, M.E., 1998. Glutathione: An overview of biosynthesis and modulation. Chem. Biol. Interact. 112, 1-14.

Anfang, N., Brajkovich, M. \& Goddard, M.R., 2009. Co-fermentation with Pichia kluyveri increases varietal thiol concentrations in Sauvignon blanc. Aust. J. Grape Wine Res. 15, 1-8.

Arrehnius, S.P., McCloskey, L.P. \& Sylvan, M., 1996. Chemical markers for aroma of Vitis vinifera var. Chardonnay regional wines. J. Agric. Food Chem. 44, 1085-1090.

Bauernfeind, J.C. \& Pinkert, D.M., 1970. Food processing with added ascorbic acid. In: Chichester, C.O. (ed.). Advances in food research. vol. 18. Academic Press, London. pp. $219-315$

Bayonove, C. \& Cordonnier, R., 1971. Recherches sur l'arôme du muscat. III. Étude de la fraction terpénique. Ann. Technol. Agric. 20, 247-355.

Beech, F.W., Burroughs, L.F., Timberlake, C.F. \& Whiting, G.C., 1979. Progrès récents sur l'aspect chimique et l'action antimicrobienne de l'anhydride sulfureux $\left(\mathrm{SO}_{2}\right)$. Bulletin de L'O.I.V. 52, 1001-1022.

Belitz, H.-D., Grosch, W. \& Schieberle, P., 2009. Food chemistry. Springer, Berlin \& Heidelberg.

Benkwitz, F., Nicolau, L., Lund, C., Beresford, M., Wohlers, M. \& Kilmartin, P.A., 2012a. Evaluation of key odorants in Sauvignon blanc wines using three different methodologies. J. Agric. Food Chem. 60, 6293-6302.

Benkwitz, F., Tominaga, T., Kilmartin, P.A., Lund, C., Wohler, M. \& Nicolau, L., 2012b. Identifying the chemical composition related to the distinct aroma characteristics of New Zealand Sauvignon blanc wines. Am. J. Enol. Vitic. 63, 62-72.

Berg, H.W. \& Akiyoshi, M., 1956. Some factors involved in browning of white wine. Am. J. Enol. Vitic. 7, 1-7. 
Bertrand, A., 1968. Utilisation de la chromatographie en phase gazeuse pour le dosage des constituants volatils du vin. Thesis, University of Bordeaux (Bordeaux), France.

Blake, A., Kotseridis, Y., Brindle, I.D., Inglis, D. \& Pickering, G.J., 2010. Effect of light and temperature on 3-alkyl-2-methoxypyrazine concentration and other impact odourants of Riesling and Cabernet franc wines during bottle ageing. Food Chem. 119, 935-944.

Blake, A., Kotseridis, Y., Brindle, I.D., Inglis, D., Sears, M. \& Pickering, G.J., 2009. Effect of closure and packaging type on 3-alkyl-2-methoxypyrazines and other impact odorants of Riesling ad Cabernet frans wines. J. Agric. Food Chem. 57, 4680-4690.

Blanchard, L., Darriet, P. \& Dubourdieu, D., 2004. Reactivity of 3-mercaptohexanol in red wine: Impact of oxygen, phenolic fractions, and sulfur dioxide. Am. J. Enol. Vitic. 55, 115-120.

Bouchilloux, P., Darriet, P., Henry, R., Lavigne-Cruège, V. \& Dubourdieu, D., 1998. Identification of volatile and powerful odorous thiols and Bordeaux red wine varieties. J. Agric. Food Chem. 46, 3095-3099.

Boulton, R.B., Singleton, V.L., Bisson, L.F. \& Kunkee, R.E., 1996. Principles and practices of winemaking. Chapman \& Hall, New York.

Bradshaw, M.P., Cheynier, V., Scollary, G.R. \& Prenzler, P.D., 2003. Defining the ascorbic acid crossover from anti-oxidant to pro-oxidant in a model wine matrix containing (+)-catechin. J. Agric. Food Chem. 51, 41264132 .

Bradshaw, M.P., Scollary, G.R. \& Prenzler, P.D., 2001. Ascorbic acidinduced browning of $(+)$-catechin in a model wine system. J. Agric. Food Chem. 49, 934-939.

Bradshaw, M.P., Scollary, G.R. \& Prenzler, P.D., 2004. Examination of the sulfur dioxide-ascorbic acid anti-oxidant system in a model white wine matrix. J. Sci. Food Agric. 84, 318-324.

Brajkovich, M., Tibbits, N., Peron, G., Lund, C.M., Dykes, S.I., Kilmartin, P.A. \& Nicolau, L., 2005. Effect of screwcap and cork closures on $\mathrm{SO}_{2}$ levels and aromas in Sauvignon blanc wine. J. Agric. Food Chem. 53, 10006-10011.

Burroughs, L.F. \& Sparks, A.H., 1973. Sulphite-binding power of wines and ciders. I. Equilibrium constants for the dissociation of carbonyl bisulphite compounds. J. Sci. Food Agric. 24, 187-198.

Buttery, R.G., Seifert, R.M., Guadagni, D.G. \& Ling, L.C., 1969. Characterization of some volatile constituents of bell peppers. J. Agric. Food Chem. 17, 1322-1327.

Câmara, J.S., Alves, M.A. \& Marques, J.C., 2006. Changes in volatile composition of Madeira wines during their oxidative aging. Anal. Chim. Acta 563, 188-197.

Câmara, J.S., Marques, J.C., Alves, M.A. \& Silva Ferreira, A.C., 2004. 3-Hydroxy-4,5-dimethyl-2( $5 H)$-furanone levels in fortified Madeira wines: Relationship to sugar content. J. Agric. Food Chem. 52, 6765-6769.

Campo, E., Cacho, J. \& Ferreira, V., 2008. The chemical characterization of the aroma of dessert and sparkling white wines (Pedro Ximénez, Fino, Sauternes and Cava) by gas-chromatography-olfactometry and chemical quantitative analysis. J. Agric. Food Chem. 56, 2477-2484.

Campo, E., Ferreira, V., Escudero, A. \& Cacho, J., 2005. Prediction of wine sensory properties related to grape variety from dynamic-headspace gas chromatography-olfactory data. J. Agric. Food Chem. 53, 5682-5690.

Capone, D.L. \& Jeffery, D.W., 2011. Effects of transporting and processing Sauvignon blanc grapes on 3-mercaptohexan-1-ol precursor concentrations J. Agric. Food Chem. 59, 4659-4667.

Capone, D.L., Sefton, M.A., Hayasaka, Y. \& Jeffery, D.W., 2010. Analysis of precursors to wine odorant 3-mercaptohexan-1-ol using HPLC-MS/MS: Resolution and quantitation of diastereomers of 3-S-cysteinylhexan-1-ol and 3-S-glutathionylhexan-1-ol. J. Agric. Food Chem. 58, 1390-1395.
Castellari, M., Simonato, B., Tornielli, G.B., Spinelli, P. \& Ferrarini, R., 2004. Effects of different enological treatments on dissolved oxygen in wines. Ital. J. Food Sci. 16, 387-396.

Cheynier, V. \& Van Hulst, M.W.J., 1988. Oxidation of trans-caftaric acid and 2-S-glutathionyl caftaric acid in model solutions. J. Agric. Food Chem. $36,10-15$.

Cheynier, V., Trousdale, E.K., Singleton, V.L., Salgeus, M.J. \& Wylde, R., 1986. Characterization of 2-S-glutathionylcaftaric acid and its hydrolysis in relation to grape wines. J. Agric. Food Chem. 34, 217-221.

Choné, X., 2001. Contribution à l'étude des terroirs de Bordeux: étude des déficits hydriques modérés, de l'alimentation en azote et de leurs effets sur le potentiel aromatique des raisins de Vitis vinifera L. cv. Sauvignon blanc. Thesis, University of Bordeux (Bordeaux), France.

Choné, X., Lavigne-Cruège, V., Tominaga, T., Van Leewin, C., Castagnede, C., Saucier, C. \& Dubourdieu, D., 2006. Effect of vine nitrogen status on grape aromatic potential: Flavour precursors (S-cysteine conjugates), glutathione and phenolic content in Vitis vinifera L. cv. Sauvignon blanc grape juice. J. Int. Sci. Vigne Vin. 40, 1-6.

Chrisholm, M.G., Guiher, L.A. \& Zaczkiewicz, S.M., 1995. Aroma characteristics of aged Vidal blanc wine. Am. J. Enol. Vitic. 46, 56-62.

Cilliers, J.J.L. \& Singleton, V.L., 1989. Nonenzymatic autooxidative phenolic browning reactions in a caffeic acid model system. J. Agric. Food Chem. 37, 890-896.

Cilliers, J.J.L. \& Singleton, V.L., 1990. Caffeic acid autoxidation and the effects of thiols. J. Agric. Food Chem. 38, 1789-1796.

Clark, A.C., Pedretti, F., Prenzler, P.D. \& Scollary, G.R., 2008. Impact of ascorbic acid on the oxidative colouration and associated reactions of a model wine solution containing (+)-catechin, caffeic acid and iron. Aust. J. Grape Wine Res. 14, 238-249.

Coetzee, C., 2014. Oxidation treatments affecting Sauvignon blanc wine's sensory and chemical composition. Thesis, Department of Viticulture and Oenology, Stellenbosch University, Private Bag X1, 7602 Matieland (Stellenbosch), South Africa.

Coetzee, C. \& Du Toit, W.J., 2012. A comprehensive review on Sauvignon blanc aroma with a focus on certain positive volatile thiols. Food Res. Int. 45, 287-298.

Coetzee, C., Brand, J., Emerton, G., Jacobson, D., Silva Ferreira, A.C. \& Du Toit, W.J., 2015a. Sensory interaction between 3-mercaptohexan-1-ol, 3-isobutyl-2-methoxypyrazine and oxidation-related compounds. Aust. J. Grape Wine Res. doi:10.1111/ajgw.12133

Coetzee, C., Brand, J., Jacobson, D. \& Du Toit, W.J., 2015b. The sensory effect of acetaldehyde on the perception of 3-mercaptohexan-1-ol and 3-isobutyl-2-methoxypyrazine. Aust. J. Grape Wine Res. (submitted for publication).

Coetzee, C., Lisjak, K., Nicolau, L., Kilmartin, P.A. \& Du Toit, W.J., 2013. Oxygen and sulfur dioxide additions to Sauvignon blanc must: Effect on must and wine composition. Flavour Fragr. J. 28, 155-167.

Collin, S., Nizet, S., Bouuaert, T.C. \& Despatures, P.-M., 2012. Main odorants in Jura flor-sherry wines. Relative contributions of sotolon, abhexon, and theaspirane-derived compounds. J. Agric. Food Chem. 60, 380-387.

Cooper, M., 2008. Wine atlas of New Zealand. Hodder, Moa, Auckland, New Zealand.

Culleré, L., Cacho, J. \& Ferreira, V., 2007. An assessment of the role played by some oxidation-related aldehydes in wine aroma. J. Agric. Food Chem. $55,876-881$.

Cutzach, I., Chatonnet, P. \& Dubourdieu, D., 1998. Rôle du sotolon dans l'arôme des vins doux naturels, influence des conditions d'élevage et de vieillissement. J. Int. Sci. Vigne Vin. 32, 223-233. 
Cutzach, I., Chatonnet, P. \& Dubourdieu, D., 1999. Study the mechanisms of some volatile compounds during aging of sweet fortified wines. J. Agric. Food Chem. 47, 2837-2846.

Danilewicz, J.C., 2007. Interaction of sulfur dioxide, polyphenols, and oxygen in a wine-model system: Central role of iron and copper. Am. J. Enol. Vitic. 58, 53-60.

Danilewicz, J.C., Seccombe, J.T. \& Whelan, J., 2008. Mechanism of interaction of polyphenols, oxygen, and sulphur dioxide in model wine and wine. Am. J. Enol. Vitic. 59, 128-136.

Darriet, P., Tominaga, T., Lavigne, V., Boidron, J. \& Dubourdieu, D., 1995. Identification of a powerful aromatic compound of Vitis vinifera L. var Sauvignon wines: 4-Mercapto-4-methylpentan-2-one. Flavour Fragr. J. 10, 385-392.

Daudt, C.E. \& Ough, C.S., 1973. Variations in some volatile acetate esters formed during grape juice fermentation temperature, $\mathrm{SO}_{2}$, yeast strain, and grape variety. Am. J. Enol. Vitic. 24, 130-135.

Dickinson, J.R., Lanterman, M.M., Danner, D.J., Paerson, B.M., Sanz, P., Harrison, S.J. \& Hewlins, J.E., 1997. A 13C nuclear magnetic resonance investigation of the metabolism of leucine to isoamyl alcohol in Saccharomyces cerevisiae. J. Biol. Chem. 272, 26871-26878.

Dickinson, J.R., Salgado, L.E. \& Hewlins, J.E., 2003. The catabolism of amino acids to long chain and complex alcohols in Saccharomyces cerevisiae. J. Biol. Chem. 278, 8028-8034

Doyle, M. \& Beuchat, L., 2007. Food microbiology: Fundamentals and frontiers. ASM Press, Washington, DC.

Drysdale, G.S. \& Fleet, G.H., 1988. Acetic acid bacteria in winemaking: A review. Am. J. Enol. Vitic. 39, 143-154.

Dubourdieu, D., Tominaga, T., Masneuf, I., Peyrot des Gachons, C. \& Murat, M.L., 2006. The role of yeast in grape flavour development during fermentation: The example of Sauvignon blanc. Am. J. Enol. Vitic. 57, 8188

Du Toit, W.J., Lisjak, K., Stander, M. \& Prevoo, D., 2007. Using LC-MSMS to assess glutathione levels in South African white grape juices and wines made with different levels of oxygen. J. Agric. Food Chem. 55, 2765-2769.

Escudero, A., Asencio, E., Cacho, J. \& Ferreira, V., 2002. Sensory and chemical changes of young white wines stored under oxygen. An assessment of the role played by aldehydes and some other important odorants. Food Chem. 77, 325-331

Escudero, A., Cacho, J. \& Ferreira, V., 2000a. Isolation and identification of odourants generated in wine during its oxidation: A gas-chromatographyolfactometry study. Eur. Food Res. Technol. 211, 105-110.

Escudero, A., Cacho, J. \& Ferreira, V., 2011. Isolation and identification of odorants generated in wine during its oxidation: a gas chromatographyolfactometric study. Eur. Food Res. Technol. 105-110.

Escudero, A., Campo, E., Farina, L., Cacho, J. \& Ferreira, V., 2007. Analytical characterization of the aroma of five premium red wines. Insights into the role of odor families and the concept of fruitiness of wines. J. Agric. Food Chem. 55, 4501-4510.

Escudero, A., Hernandez-Orte, P., Cacho, J. \& Ferreira, V., 2000b. Clues about the role of methional as character impact odorant of some oxidized wines. J. Agric. Food Chem. 48, 4268-4272.

Es-Safi, N., Le Guernevé, C., Labarbe, B., Fulcrand, H., Cheynier, V. \& Moutounet, M., 1999. Structure of a new xanthylium salt derivative. Tetrahedron Lett. 40, 5869-5872.

Fedrizzi, B., Pardon, K.H., Sefton, M.A., Elsey, G.M. \& Jeffery, D.W., 2009 First identification of 4-S-glutathionyl-4-methylpentan-2-one, a potentia precursor of 4-mercapto-4-methylpentan-2-one, in Sauvignon blanc juice. J. Agric. Food Chem. 57, 991-995.
Fedrizzi, B., Zapparoli, G., Finato, F., Tosi, E., Turri, A., Azzolini, M \& Versini, G., 2011. Model aging and oxidation effects on varietal, fermentative, and sulphur compounds in a dry botrytized red wine. J. Agric. Food Chem. 59, 1804-1813.

Fernandez-Zurbano, P., Ferreira, V., Pena, C., Escudero, A., Serrano, F. \& Cacho, J., 1995. Prediction of oxidative browning in white wines as a function of their chemical composition. J. Agric. Food Chem. 43, 28132817

Ferreira, V., Escudero, A., Fernández, P.E. \& Cacho, J., 1997. Changes in the profile of volatile compounds in wines stored under oxygen and their relationship with the browning process. Z. Lebensm. Unters. Forsch. 205, 392-396.

Ferreira, V., Ortin, N., Escudero, A., Lopez, R. \& Cacho, J., 2002. Chemical characterization of the aroma of Grenache rosé wines: Aroma extract dilution analysis, quantitative determination, and sensory reconstitution studies. J. Agric. Food Chem. 50, 4048-4054.

Francis, I.L. \& Newton, J.L., 2005. Determining wine aroma from compositional data. Aust. J. Grape Wine Res. 11, 114-126.

Frivik, S.K. \& Ebeler, S.E., 2003. Influence of sulfur dioxide on the formation of aldehydes in white wine. Am. J. Enol. Vitic. 54, 31-38.

Garde-Cerdán, T. \& Ancín-Azpilicueta, C., 2007. Effect of $\mathrm{SO}_{2}$ on the formation and evolution of volatile compounds in wines. Food Control. 18, $1501-1506$

Ghidossi, R., Poupot, C., Thibon, C., Pons, A., Darriet, L., Riquier, G., De Revel, G. \& Mietton Peuchot, M., 2012. The influence of packaging on wine conservation. Food Control. 23, 302-311.

Godden, P., Leigh, F., Field, J., Gishen, M., Coulter, A., Valente, P., Høj, P. \& Robinson, E., 2001. Wine bottle closures: Physical characteristics and effect on composition and sensory properties of a Semillon wine. 1. Performance up to 20 months post-bottling. Aust. J. Grape Wine Res. 7, 64-105.

Goniak, O.J. \& Noble, A.C., 1987. Sensory study of selected volatile sulfur compounds in white wine. Am. J. Enol. Vitic. 38, 223-227.

Green, J.A., Parr, W.V., Breitmeyer, J., Valentin, D. \& Sherlock, R., 2011. Sensory and chemical characterisation of Sauvignon blanc wine: Influence of source of origin. Food Res. Int. 44, 2788-2797.

Guichard, E., Etiévant, P.X., Henry, R. \& Mosandl, A., 1992. Enantiomeric ratios of pantolactone, solerone, 4-carboethoxy-4-hydroxy-butyrolactone, and of sotolon, a flavour impact compound of flor-sherry and botrytized wines. Z. Lebensm. Unters. Forsch. 195, 540-544.

Halliday, J. \& Johnson, H., 1992. The art and science of wine. Mitchell Beazley, London.

Harsch, M.J., Benkwitz, F., Frost, A., Colonna-Ceccaldi, B. \& Gardner, R.C., 2013. New precursor of 3-mercaptohexan-1-ol in grape juice: Thiolforming potential and kinetics during early stages of must fermentation. J. Agric. Food Chem. 61, 3703-3713.

Hein, K., Ebeler, S.E. \& Heymann, H., 2009. Perception of fruity and vegetal aromas in red wine. J. Sens. Stud. 24, 441-455.

Henschke, P.A. \& Jiranek, V., 1993. Yeasts: Growth during fermentation. In: Fleet, G.H. (ed.). Wine microbiology and biotechnology. Hardwood Academic Publishers, Chur, Switzerland. pp. $27-54$.

Herbst, M., 2010. Investigation into the aroma stability of New Zealand Sauvignon blanc. Thesis, University of Auckland (Auckland), New Zealand.

Herbst, M., Kilmartin, P.A. \& Nicolau, L., 2008. Aroma stability in Sauvignon blanc wines. Aust. N.Z. Grapegrow. Winemak. 6, 66-72.

Herbst-Johnstone, M., Nicolau, L. \& Kilmartin, P.A., 2011. Stability of varietal thiols in commercial Sauvignon blanc wines. Am. J. Enol. Vitic. $62,495-502$. 
Jackowetz, J.N. \& De Orduña, M., 2013. Survey of $\mathrm{SO}_{2}$ binding carbonyls in 237 red and white table wines. Food Control 32(2), 687-692.

Jackson, R.S., 2008. Wine science: Principles and applications. Elsevier/ Academic Press, Amsterdam.

Janeš, L., Lisjak, K. \& Vanzo, A., 2010. Determination of glutathione content in grape juice and wine by high performance liquid chromatography with fluorescence detection. Anal. Chim. Acta. 674, 239-242.

Jocelyn, P.C., 1972. Biochemistry of the SH group; the occurrence, chemical properties, metabolism and biological function of thiols and disulphides. Academic Press, London, UK.

Kielhöfer, E. \& Würdig, G., 1960. Die an aldehyd gebundene schweflige säure im wein. I. Mitteilung: Aldehydbildung und enzymatische und nichtenzymatische alkohol-oxidation. II. Acetaldehydbildung bei der gärung. Weinberg Keller 7, 16-22; 50-61.

Kilmartin, P.A., Zou, H. \& Waterhouse, A.L., 2001. A cyclic voltammetry method suitable for characterizing antioxidant properties of wine and wine phenolics. J. Agric. Food Chem. 49, 1957-1965.

Kilmartin, P.A., Zou, H. \& Waterhouse, A.L., 2002. Correlation of wine phenolic composition versus cyclic voltammetry response. Am. J. Enol. Vitic. 53, 294-302.

King, E.S., Osidacz, P., Curtin, C., Bastian, S.E.P. \& Francis, I.L., 2011. Assessing desirable levels of sensory properties in Sauvignon Blanc wines - consumer preferences and contribution of key aroma compounds. Aust. J. Grape Wine Res. 17, 169-180.

Kleinhans, D., 1982. Sensitivity of asthmatics against sulphur compounds in food, wine and injection solutions. Dtsch. Med. Wochenschr. 107, 14091411 .

König, T., Gutsche, B., Hartl, M., Hübscher, R., Schreier, P. \& Schwab, W., 1999. 3-Hydroxy-4,5-dimethyl-2(5H)-furanone (sotolon) causing an offflavor: Elucidation of its formation pathways during storage of citrus soft drinks. J. Agric. Food Chem. 47, 3288-3291.

Kotseridis, Y. \& Baumes, R., 2000. Identification of impact odorants in Bordeaux red grape juice, in the commercial yeast used for its fermentation, and in the produced wine. J. Agric. Food Chem. 48, 400-406.

Kotseridis, Y., Ray, J., Augier, C. \& Baumes, R., 2000. Quantitative determination of sulfur containing wine odorants at sub-ppb levels. 1. Synthesis of the deuterated analogues. J. Agric. Food Chem. 48, 5819-5823.

Kotseridis, Y., Spink, M., Brindle, I.D., Blake, A., Sears, M., Chen, X., Soleas, G., Inglis, D. \& Pickering, G.J., 2008. Quantitative analyses of 3-alkyl-2-methoxypyrazines in juice and wine using stable isotope labelled internal standard assay. J. Chromatogr. A. 1190, 294-301.

Kreitman, G.Y., Laurie, F. \& Elias, R., 2013. Investigation of ethyl radical quenching by phenolics and thiols in model wine. Am. J. Enol. Vitic. 61, 685-692.

Kritzinger, E.C., Bauer, F.F. \& Du Toit, W.J., 2013a. Role of glutathione in winemaking: A review. J. Agric. Food Chem. 61, 269-277.

Kritzinger, E.C., Stander, M. \& Du Toit, W.J., 2013b. Assessment of glutathione levels in model solution and grape ferments supplemented with glutathione-enriched inactive dry yeast preparations using a novel UPLCMS/MS method. Food. Addit. Contam. Part A. 30, 80-92.

Kwiatkowski, M., Skouroumounis, G.K., Lattey, K.A. \& Waters, E.J., 2007. The impact of closures, including screw cap with three different headspace volumes, on the composition, colour and sensory properties of a Cabernet Sauvignon wine during two years' storage. Aust. J. Grape Wine Res. 13, $81-94$

Lacey, M.J., Allen, M.S., Harris, R.L.N. \& Brown, W.V., 1991. Methoxypyrazines in Sauvignon blanc grapes and wines. Am. J. Enol. Vitic. 42, 103-108
Lachenmeier, D.W. \& Sohnuis, E-M., 2008. The role of acetaldehyde outside ethanol metabolism in the carcinogenicity of alcoholic beverages: Evidence from a large chemical survey. Food Chem. Toxicol. 46, 2903-2911.

Lambrechts, M.G. \& Pretorius, I.S., 2000. Yeast and its importance to wine aroma - A review. S. Afr. J. Enol. Vitic. 21, 97-129.

Lambropoulos, I. \& Roussis, I., 2007. Inhibition of decrease of volatile esters and terpenes during storage of white wine and a model white wine medium by caffeic acid and gallic acid. Food Res. Int. 40, 176-181.

Laurie, F., Zúñiga, M.C., Carrasco-Sánchez, V., Santos, L., Cañete, A., Olea-Azar, C., Ugliano, M. \& Agosin, E., 2012. Reactivity of 3-sulfanyl1 -hexanol and catechol-containing phenolics in vitro. Food Chem. 131, 1510-1516.

Lavigne, V., Pons, A., Darriet, P. \& Dubourdieu, D., 2008. Changes in sotolon content of dry white wines during barrel and bottle aging. J. Agric. Food Chem. 56, 2688-2693.

Lavigne-Cruège, V. \& Dubourdieu, D., 2003. Rôle du glutathion sur l'évolution aromatique des vins blancs secs. Presented at the 7e Symposium International d'Oenologie, Arcachon, France December, 2003.

Lawless, H.T. \& Heymann, H., 1998. Sensory evaluation food, principles and practice. Chapman and Hall, New York, USA.

Lee, D.-H., Kang, B.-S. \& Park, H.-J., 2011. Effect of oxygen on volatile and sensory characteristics of Cabernet Sauvignon during secondary shelf life. J. Agric. Food Chem. 59, 11657-11666.

Li, H., Guo, A. \& Wang, H., 2008. Mechanisms of oxidative browning of wine. Food Chem. 108, 1-13.

Lilly, M., Lambrechts, M.G. \& Pretorius, I.S., 2000. Effect of increased yeast alcohol acetyltransferase activity on flavor profiles of wine and distillates. Appl. Environ. Microbiol. 66, 744-753.

Limmer, A., 2005. Suggestions for dealing with post-bottling sulfides. Aust. N.Z. Grapegrow. Winemak. 476, 65-74.

Liu, S-Q. \& Pilone, G.J., 2000. An overview of formation and roles of acetaldehyde in winemaking with emphasis on microbial implications. Int. J. Food Sci. Technol. 35, 49-61.

Lopes, P., Saucier, C. \& Glories, Y., 2005. Nondestructive colorimetric method to determine the oxygen diffusion rate through closures used in winemaking. J. Agric. Food Chem. 53, 6967-6973.

Lopes, P., Silva, M.A., Pons, A., Tominaga, T., Lavigne, V., Saucier, C., Darriet, P., Teissedre, P.L. \& Dubourdieu, D., 2009. Impact of oxygen dissolved at bottling and transmitted through closures on the composition and sensory properties of a Sauvignon blanc wine during bottle storage. J. Agric. Food Chem. 57, 10261-10270.

Loscos, N., Hernandez-Orte, P., Cacho, J. \& Ferreira, V., 2007. Release and formation of varietal aroma compounds during alcoholic fermentation from nonfloral grape odorless flavor precursors fractions. J. Agric. Food Chem. $55,6674-6684$.

Loscos, N., Hernandez-Orte, P., Cacho, J. \& Ferreira, V., 2010. Evolution of the aroma composition of wines supplemented with grape flavour precursors from different varietals during accelerated wine aging. Food Chem. 120, 205-216.

Loyaux, D., Roger, S. \& Adda, J., 1981. The evolution of Champagne volatiles during ageing. J. Sci. Food Agric. 32, 1254-1258.

Lund, C.M., Nicolau, L., Gardner, R.C. \& Kilmartin, P.A., 2009a. Effect of polyphenols on the perception of key aroma compounds from Sauvignon blanc wines. Aust. J. Grape Wine Res. 15, 18-26. 
Lund, C.M., Thompson, M.K., Benkwitz, F., Wohler, M.W., Triggs, C.M., Gardner, R., Heymann, H. \& Nicolau, L., 2009b. New Zealand Sauvignon blanc distinct flavor characteristics: Sensory, chemical, and consumer aspects. Am. J. Enol. Vitic. 60, 1-12.

Maga, J.A., 1989. Sensory and stability properties of added methoxypyrazines to model and authentic wines. Proc. 6th Intern. Flavor Conf.: Flavors and Off-flavors. Rethymnon, Crete, Greece, July 1989. pp. $61-70$.

Maggu, M., Winz, R., Kilmartin, P.A., Trought, M.C.T. \& Nicolau, L., 2007. Effect of skin contact and pressure on the composition of Sauvignon blanc must. J. Agric. Food Chem. 55, 10281-10288.

Makhotkina, O. \& Kilmartin, P.A., 2012. Hydrolysis and formation of volatile esters in New Zealand Sauvignon blanc wine. Food Chem. 135, 486-493.

Marais, J., 1978. The effect of $\mathrm{pH}$ on esters and quality of Colombar wine during maturation. Vitis 19, 151-154.

Marais, J., 1983. Terpenes in the aroma of grapes and wines: A review. S. Afr. J. Enol. Vitic. 4, 49-60.

Marais, J., 1994. Sauvignon blanc cultivar aroma - A review. S. Afr. J. Enol. Vitic. 15, 41-45.

Marais, J., 1998. Effect of grape temperature, oxidation and skin contact on Sauvignon blanc juice and wine composition and wine quality. S. Afr. J. Enol. Vitic. 19, 10-16.

Marais, J., 2001. Effect of grape temperature and yeast strain on Sauvignon blanc wine aroma composition and quality. S. Afr. J. Enol. Vitic. 22, 47-50.

Marais, J. \& Pool, H.J., 1980. Effect of storage time and temperature on the volatile composition and quality of dry white table wines. Vitis 19, 151-164.

Marais, J. \& Swart, E., 1999. Sensory impact of 2-methoxy-3isobutylpyrazine and 4-mercapto-4-methylpentan-2-one added to a neutral Sauvignon blanc wine. S. Afr. J. Enol. Vitic. 20, 77-79

Marais, J., Minnaar, P. \& October, F., 1998. 2-Methoxy-3-isobutylpyrazine levels in a spectrum of South African Sauvignon blanc wines. S. Afr. J. Enol. Vitic. 19, 10-16.

Margalit, Y., 1997. Concepts in wine chemistry. The Wine Appreciation Guild, San Francisco.

Margalith, P.Z., 1981. Flavour microbiology. Charles C. Thomas Publishers, Springfield, Illinois.

Martin, B. \& Etiévant, P.X., 1991. Quantitative determination of solerone and sotolon in flor sherries by two-dimensional-capillary GC. J. High Resolut. Chrom. 14(2), 133-135.

Martin, B., Etiévant, P.X., Le Queré, L. \& Schlich, P., 1992. More clues about the sensory impact of sotolon in flor sherry wines. J. Agric. Food Chem. 40, 475-478.

Martínez, P., Valcárcel, M.J., Piérez, L. \& Benítez, T., 1998. Metabolism of Saccharomyces cerevisiae flor yeasts during fermentation and biological aging of fino sherry: By-products and aroma compounds. Am. J. Enol. Vitic. 49, 240-250.

Masneuf-Pomarède, I., Mansour, C., Murat, M.L., Tominaga, T. \& Dubourdieu, D., 2006. Influence of fermentation temperature on volatile thiols concentrations in Sauvignon blanc wines. Int. J. Food Microbiol. 108, 385-390.

Masuda, M., Okawa, E., Nishimura, K. \& Yunome, H., 1984. Identification of 4,5-dimethyl-3-hydroxy-2 $(5 H)$-furanone (sotolon) and ethyl 9-hydroxynonanoate in botrytised wine and evaluation of the roles of compounds characteristic. Agric. Biol. Chem. 48, 2707-2010.

Meilgaard, M.C., 1975. Flavour chemistry of beer. Part II: Flavour and threshold of 239 aroma volatiles. M. B. A. A., T. Q. 12(3), 151-168.
Miyake, T. \& Shibamoto, T., 1993. Quantitative analysis of acetaldehyde in foods and beverages. J. Agric. Food Chem. 41, 1968-1970.

Monagas, M., Bartolomé, B. \& Gómez-Cordovés, C., 2005. Updated knowledge about the presence of phenolic compounds in wine. Crit. Rev. Food Sci. Nutr. 45, 85-118

Moutounet, M., Rabier, P., Puench, J.L., Verette, E. \& Barillére, J.M., 1989. Analysis of HPLC of extractable substances of oak wood - Application to a Chardonnay wine. Sci. Aliments 9, 35-51.

Murat, M.L., 2005. Recent findings on rosé aromas. Part 1: Identifying aromas studying the aromatic potential of grapes and juice. Aust. N.Z Grapegrow. Winemak. 497a, 64-76.

Murat, M.L., Masneuf, I., Darriet, I., Lavigne, V., Tominaga, T. \& Dubourdieu, D., 2001a. Effect of Saccharomyces cerevisiae yeast strains on the liberation of volatile thiols in Sauvignon blanc wine. Am. J. Enol. Vitic. 52, 136-139.

Murat, M.L., Tominaga, T. \& Dubourdieu, D., 2001b. Assessing the aromatic potential of Cabernet Sauvignon and Merlot musts used to produce rosé wine by assaying the cysteinylated precursor of 3-mercaptohexan-1-ol J. Agric. Food Chem. 49, 5412-5417.

Murat, M.L., Tominaga, T., Saucier, C., Glories, Y. \& Dubourdieu, D., 2003. Effect of anthocyanins on stability of a key odorous compound, 3-mercaptohexan-1-ol, in Bordeaux rosé wines. Am. J. Enol. Vitic. 54, 135138.

Nguyen, D.-D., Nicolau, L., Dykes, S.I. \& Kilmartin, P.A., 2010. Influence of microoxygenation on reductive sulfur off-odours and color development in Cabernet Sauvignon wine. Am. J. Enol. Vitic. 61, 457-464.

Nicolau, L., Benkwitz, F. \& Tominaga, T., 2006. Characterising the aroma of New Zealand Sauvignon blanc. Aust. N.Z. Grapegrow. Winemak. 509, 46-49.

Nikolantonaki, M. \& Waterhouse, A.L., 2012. A method to quantify quinone reaction rates with wine relevant nucleophiles: A key to the understanding of oxidative loss of varietal thiols. J. Agric. Food Chem. 60, 8484-8491.

Nikolantonaki, M., Chichuc, I., Teissedre., P.L. \& Darriet, P., 2010 Reactivity of volatile thiols with polyphenols in a wine-model medium: Impact of oxygen, iron, and sulfur dioxide. Anal. Chim. Acta. 660, 102-109.

Nikolantonaki, M., Jourdes, M., Shinoda, K., Teissedre, P.L., Quideau, S. \& Darriet, P., 2012. Identification of adducts between an odoriferous volatile thiol and oxidized grape phenolic compounds: Kinetic study of adduct formation under chemical and enzymatic oxidation conditions. J. Agric Food Chem. 60, 2647-2656.

Noble, A.C., Arnold, R.A., Buechsenstein, J., Leach, E.J., Schmidt, J.O. \& Stern, P.M., 1987. Modification of a standardized system of wine aroma terminology. Am. J. Enol. Vitic. 38, 143-146.

Nygaard, M., 2010. Oxygen management from grapes to glass. Wine Ind. J. 25, 24-28.

Nygaard, M., Osidacz, P., Roget, W., Francis, L., Vidal, S. \& Aagaard, O., 2010. The effect of closure choice on consumer preference rating of wines Aust. N.Z. Grapegrow. Winemak. 563, 55-60.

Nykänen, L., 1986. Formation and occurrence of flavor compounds in wine and distilled alcoholic beverages. Am. J. Enol. Vitic. 37, 84-96.

Nykänen, L. \& Suomalainen, H., 1982. Aroma of beer, wine and distilled alcoholic beverages. Reidel, Dordrecht

O’Brien, V., Francis, L. \& Osidacz, P., 2009. Packaging choices affect consumer enjoyment of wines. Wine Ind. J. 24, 48-54

Oliveira, A.C., Silva Ferreira, A.C., Guedes de Pinho, P. \& Hogg, T.A. 2002. Development of a potentiometric method to measure the resistance to oxidation of white wines and the antioxidant power of their constituents. J. Agric. Food Chem. 50, 2121-2124. 
Oliveira, J.M., Faria, M., Sá, F., Barros, F. \& Araújo, I.M., 2006. C 6 -alcohols as varietal markers for assessment of wine origin. Anal. Chim. Acta. 563, 300-309.

Oszmianski, J., Sapis, J.C. \& Macheix, J.J., 1985. Changes in grape seed phenols as affected by enzymic and chemical oxidation in vitro. J, Food Sci. 50, 1505 .

Papadopoulou, D. \& Roussis, I.G., 2001. Inhibition of the decline of linalool and $\alpha$-terpineol in Muscat wines by glutathione and $\mathrm{N}$-acetyl-cysteine. Ital. J. Food Sci. 13, 413-419.

Papadopoulou, D. \& Roussis, I.G., 2008. Inhibition of the decrease of volatile esters and terpenes during storage of a white wine and a model wine medium by glutathione and $\mathrm{N}$-acetylcysteine. Int. J. Food Sci. Technol. 43 , 1053-1057.

Park, S.K., Boulton, R.B., Bartra, E. \& Noble, A.C., 1994. Incidence of volatile sulfur compounds in California wines. A preliminary survey. Am. J. Enol. Vitic. 45, 341-344.

Patel, P., Herbst-Johnstone, M., Lee, S.A., Gardner, R.C., Weaver, R., Nicolau, L. \& Kilmartin, P.A., 2010. Influence of juice pressing conditions on polyphenols, antioxidants, and varietal aroma of Sauvignon blanc microferments. J. Agric. Food Chem. 58, 7280-7288.

Patrianakou, M. \& Roussis, I.G., 2013. Decrease of wine volatile aroma esters by oxidation. S. Afr. J. Enol. Vitic. 34, 241-245.

Paul, F., 1975. SO relationships in fermenting red wine mashes and musts. Proc. Fourth International Enological Symposium, Valencia, Spain. pp. 76 -85 .

Peng, Z., Duncan, B., Pocock, K.F. \& Sefton, M.A., 1998. The effect of ascorbic acid on oxidative browning of white wines and model wines. Aust. J. Grape Wine Res. 4, 127-35.

Penna, N.C., Daudt, C.E., Brendel, M. \& Henriques, J.A.P., 2001. Evolution of glutathione levels and hydroxycinnamic acid during fermentation of Sauvignon blanc, Chenin blanc, Niágara and Tannat. Alimentaria 326, 147151 .

Peyrot des Ganchos, C., Tominaga, T. \& Dubourdieu, D., 2002. Sulfur aroma precursor present in S-glutathione conjugate form: Identification of S-3-(hexan-1-ol)-glutathione in must from Vitis vinifera L. cv. Sauvignon blanc. J. Agric. Food Chem. 50, 4076-4079.

Peyrot des Ganchos, C., Van Leewin, C., Tominaga, T., Soyer, J-P., Gaudillere, J-P. \& Dubourdieu, D., 2005. Influence of water and nitrogen deficit on fruit ripening and aroma potential of Vitis vinifera L. cv. Sauvignon blanc in field conditions. J. Agric. Food Chem. 85, 73-85.

Pham, T.T., Guichard, E., Pascal, S. \& Charpentier, C., 1995. Optimal conditions for the formation of Sotolon from $\alpha$-ketobutyric acid in the French "Vin Jaune". J. Agric. Food Chem. 43, 2616-2619.

Pickering, G.J., Lin, J., Reynolds, A., Soleas, G. \& Riesen, R., 2006. The evaluation of remedial treatments for wine affected by Harmonia axyridis. Int. J. Food Sci. Technol. 41, 77-86.

Pinu, F.R., Jouanneau, S., Nicolau, L., Gardner, R.C., Villas-Boas, S.G., 2012. Concentrations of the volatile thiol 3-mercaptohexanol in Sauvignon blanc wines: No correlation with juice precursors. Am. J. Enol. Vitic. 63, 407-412.

Pons, A., Lavigne, V., Landais, Y., Darriet, P. \& Duboudieu, D., 2010. Identification of a sotolon pathway in dry white wines. J. Agric. Food Chem. 58, 7273-7279.

Pripis-Nicolau, L., De Revel, G., Bertrand, A. \& Maujean, A., 2000. Formation of flavour components by the reaction of amino acid and carbonyl compounds in mild conditions. J. Agric. Food Chem. 48, 3761-3766.

Ramey, D.D. \& Ough, C.S., 1980. Volatile ester hydrolysis or formation during storage of model solutions and wines. J. Agric. Food Chem. 28, 928934.
Rankine, B.C. \& Pocock, K.F., 1969. Influence of yeast strains on binding of sulphur dioxide in wines, and on its formation during fermentation. J. Sci. Food Agric. 20, 104-109.

Rapp, A., 1988. Studies on terpene compounds in wines. In: Charalambous, G. (ed.). Frontiers of flavor. Elsevier, Amsterdam. pp. 799 - 813.

Rapp, A. \& Mandery, H., 1986. Wine aroma. Experientia 42, 873-884.

Rauhut, D., 1993. Yeasts-production of sulfur compounds. In: Fleet, G.H. (ed.). Wine microbiology and biotechnology. Hardwood Academic, Chur, Switzerland. pp. $183-223$.

Renouil, Y., 1988. Dictionaire du vin. Sézame, Tours.

Ribéreau-Gayon, P., Boidron, J.N. \& Terrier, A., 1975. Aroma of Muscat grape varieties. J. Agric. Food Chem. 23, 1042-1047.

Ribéreau-Gayon, P., Glories, Y., Maujean, A. \& Dubourdieu, D., 2006. Handbook of enology: The chemistry of wine stabilization and treatments. John Wiley \& Sons Ltd, Chichester.

Rizzi, G.P., 2006. Formation of Strecker aldehydes from polyphenol derived quinones and $\alpha$-amino acids in a nonenzymatic model system. J. Agric. Food Chem. 54, 1893-1897.

Roland, A., Cavelier, F. \& Schneider, R., 2011. New insights in varietal thiols biogenesis in wine. Proc. International Conference Series on Wine Active Compounds. Beaune, France. pp. $21-23$.

Roland, A., Schneider, R., Guerneve, C.L., Razungles, A. \& Cavelier, F., 2010a. Identification and quantification by LC-MS/MS of a new precursor of 3-mercaptohexan-1-ol (3MH) using stable isotope dilution assay: Elements for understanding the $3 \mathrm{MH}$ production in wine. Food Chem. 121, 847-855.

Roland, A., Vialaret, J., Razungles, A., Rigou, P. \& Schneider, R., 2010 b. Evolution of $S$-cysteinylated and $S$-glutathionylated thiol precursors during oxidation of Melon B. and Sauvignon blanc musts. J. Agric. Food Chem. $58,4406-4413$.

Rossi, J.A. \& Singleton, V.L., 1966. Contribution of grape phenols to oxygen absorption and browning of white wine. Am. J. Enol. Vitic. 17, 231-239.

Roussis, I.G., Lambropoulos, I. \& Papadopoulou, D., 2005. Inhibition of the decline of volatile esters and terpenols during oxidative storage of Muscatwhite and Xinomavro-red wine by caffeic acid and N-acetyl-cysteine. J. Agric. Food Chem. 93, 485-492.

Roussis, I.G., Lambropoulos, I. \& Tzimas, P., 2007. Protection of volatiles in a wine with low sulfur dioxide by caffeic acid or glutathione. Am. J. Enol. Vitic. 58, 274-278.

Sala, C., Busto, O., Guasch, J. \& Zamora, F., 2004. Influence of vine training and sunlight exposure on the 3-alkyl-2-methoxypyrazine content in must and wines from Vitis vinifera variety Cabernet Sauvignon. J. Agric. Food Chem. 52, 3492-3497.

Salmon, J.M., Fornaison, C. \& Moutounet, M., 1999. Modification chimique des lies consécutive à l'apport d'oxygène pendant l'élevage des vins sur lies. Proc. Oenologie 99, 6eme Symposium International d'oenologie. Paris, France. pp. $428-432$.

Sarrazin, E., Dubourdieu, D. \& Darriet, D., 2007. Characterization of keyaroma compounds of botrytized wines, influence of grape botrytization. Food Chem. 103, 536-545.

Schneider, V., 2003. Alterung von Weißwein, I: Die Reduktionskraft der Hefe. Die Winzer-Zeitung 5, 40-42.

Schneider, V., 2005. Postfermentative Phase: Die Hefe nach der Gärung. Der Winzer 11, 13-18.

Schreier, P., 1979. Flavour composition of wines: A review. Crit. Rev. Food Sci. Nutr. 12, 59-111. 
Segurel, M.A., Razungles, A.J., Riou, C., Triguiero, M.G.L. \& Baumes, R., 2005. Ability of possible DMS precursors to release DMS during wine aging in the conditions of heat-alkaline treatment. J. Agric. Food Chem. 53, 2637-2645

Silva Ferreira, A.C., Barbe, J-C. \& Bertrand, A., 2002a. Heterocyclic acetals from glycerol and acetaldehyde in Port wines: Evolution with aging. J. Agric. Food Chem. 50, 2560-2564.

Silva Ferreira, A.C., Barbe, J.-C. \& Bertrand, A., 2003a. 3-Hydroxy-4,5dimethyl-2(5H)-furanone: A key odorant of the typical aroma of oxidative aged Port wine. J. Agric. Food Chem. 51, 4356-4363.

Silva Ferreira, A.C., Guedes de Pinho, P., Rodrigues, P. \& Hogg, T., 2002b. Kinetics of oxidative degradation of white wines and how they are affected by selected technological parameters. J. Agric. Food Chem. 50, 5919-5924.

Silva Ferreira, A.C., Hogg, T. \& Guedes de Pinho, P., 2003b. Identification of key odorants related to the typical aroma of oxidation-spoiled white wines. J. Agric. Food Chem. 51, 1377-1381.

Silva Ferreira, A.C., Rodrigues, P., Hogg, T. \& Guedes de Pinho, P., 2003c. Influence of some technological parameters on the formation of dimethyl sulfide, 2-mercaptoethanol, methionol, and dimethyl sulfone in port wines. J. Agric. Food Chem. 51, 727-732.

Simpson, R.F., 1978. Aroma and compositional changes in wine with oxidation, storage and ageing. Vitis 17, 274-287.

Simpson, R.F., 1982. Factors affecting oxidative browning of white wine. Vitis. 21, 233-239.

Singleton, V.L., 1987. Oxygen with phenols and related reactions in must, wines and model systems: Observations and practical implications. Am. J Enol. Vitic. 38, 69-77.

Singleton, V.L., Salgues, J., Zaya, J. \& Trousdale, E., 1985. Caftaric acid disappearance and conversion to products of enzymatic oxidation in grape must and wine. Am. J. Enol. Vitic. 36, 50-56.

Singleton, V.L., Timberlake, C.F. \& Lea, A.G.H., 1978. The phenolic cinnamates of white grapes and wines. J. Sci. Food Agr. 29, 403-410.

Singleton, V.L., Trousdale, E. \& Zaya, J., 1979. Oxidation of wines I. Young white wines periodically exposed to air. Am. J. Enol. Vitic. 30, 49-54.

Singleton, V.L., Zaya, J., Trousdale, E. \& Salgues, M., 1984. Caftaric acid in grapes and conversion to a reaction product during processing. Vitis 23, 113-120.

Skouroumounis, G.K., Kwiatkowski, M.J., Francis, I.L., Oakey, H., Capone D.L., Duncan, B., Sefton, M.A. \& Waters, E.J., 2005a. The impact of closure type and storage conditions on the composition, colour and flavour properties of a Riesling and a wooded Chardonnay wine during five years' storage. Aust. J. Grape Wine Res. 11, 369-384.

Skouroumounis, G. K., Kwiatkowski, M.J., Francis, I.L., Oakey, H., Capone, D.L., Peng, Z., Duncan, B., Sefton, M.A., Waters, E.J., 2005b. The influence of ascorbic acid on the composition, colour and flavour properties of a Riesling and a wooded Chardonnay wine during five years' storage. Aust. J. Grape Wine Res. 11, 355-368.

Soares da Costa, M., Gonçalves, C., Ferreira, A., Ibsen, C., Guedes de Pinho, P. \& Silva Ferreira, A.C., 2004. Further insights into the role of methional and phenylacetaldehyde in lager beer flavour stability. J. Agric. Food Chem. 52, 7911-7917.

Soles, R.M., Ough, C.S. \& Kunkee, R.E., 1982. Ester concentration differences in wine fermented by various species and strains of yeasts. Am. J. Enol. Vitic. 33, 94-98.

Sonni, F., Clark, A.C., Prenzler, P.D., Riponi, C. \& Scollary, G.R., 2011. Antioxidant action of glutathione and the ascorbic acid/glutathione pair in a model white wine. J. Agric. Food Chem. 59, 3940-3949.
Stone, H. \& Sidel, J.L., 1993. Sensory evaluation practices. California, USA

Subileau, M., Schneider, R., Salmon, J.M. \& Degryse, E., 2008a. New insights on 3-mercaptohexanol (3MH) biogenesis in Sauvignon blanc wines: Cys-3MH and (E)-Hexen-2-al are not the major precursor. J. Agric. Food Chem. 56, 9230-9235.

Subileau, M., Schneider, R., Salmon, J.M. \& Degryse, E., 2008 b. Nitrogen catabolite repression modulates the production of aromatic thiols characteristic of Sauvignon blanc at the level of precursor transport. FEMS Yeast Res. 8, 771-780.

Swiegers, J.H., Francis, I.L., Herderich, M.J. \& Pretorius, I.S., 2006 Meeting consumer expectations through management in vineyard and winery: The choice of yeast for fermentation offers great potential to adjust the aroma of Sauvignon blanc wine. Aust. NZ Wine Ind. J. 21, 34-42.

Swiegers, J.H., Willmott, R., Hill-Ling, A., Capone, D.L., Pardon, K.H., Elsey, G.M., Howell, K.S., De Barros Lopes, M.A., Sefton, M.A., Lilly, M. \& Pretorius, I.S., 2005. Modulation of volatile thiol and ester aromas by modified wine yeast. Proc. Weurman flavour research symposium. Roskilde, Denmark.

Takahashi, T., Tadenuma, M. \& Sato, S., 1976. 3-Hydroxy-4,5-dimethyl$2(5 \mathrm{H})$-furanone, a burnt flavouring compound from aged sake. Agric. Biol. Chem. 40, 325-330

Thibon, C., Dubourdieu, D., Darriet, P. \& Tominaga, T., 2009. Impact of noble rot on the aroma precursor of sulfanylhexanol content in Vitis vinifera L. cv Sauvignon blanc and Semillon grape juice. Food Chem. 114, 13591364.

Thurston, P.A., Taylor, R. \& Ahvenainen, J., 1981. Effects of linoleic acid supplements on the synthesis by yeast of lipids and acetate esters. J. Inst. Brew. 87, 92-95.

Tominaga, T., 2003. Contribution of benzenemethanethiol to the smoky aromas of certain Vitis vinifera wines. J. Agric. Food Chem. 51, 1373-1376.

Tominaga, T., Baltenweck-Guyot, R., Peyrot des Gachons, C. \& Dubourdieu, D., 2000. Contribution of volatile thiols to the aromas of white wines made from several Vitis vinifera grape varieties. Am. J. Enol. Vitic. 51, 178-181.

Tominaga, T., Darriet, P. \& Dubourdieu, D., 1996. Identification of 3-mercaptohexyl acetate in Sauvignon wine, a powerful aromatic compound exhibiting box-tree odor. Vitis. 35, 207-210.

Tominaga, T., Furrer, A., Henry, R. \& Dubourdieu, D., 1998a. Identification of new volatile thiols in the aroma of Vitis vinifera L. var. Sauvignon blanc wines. Flavour Fragr. J. 13, 159-162.

Tominaga, T., Guimbertau, G. \& Dubourdieu, D., 2003. Role of certain volatile thiols in the bouquet of aged Champagne wines. J. Agric. Food Chem. 51, 1016-1020.

Tominaga, T., Masneuf, I. \& Dubourdieu, D., 2004. Powerful aromatic volatile thiols in wines made from several Vitis vinifera $\mathrm{L}$. cv. Sauvignon blanc. Proc. ACS Symposium Series. pp. $314-337$.

Tominaga, T., Peyrot des Gachons, C. \& Dubourdieu, D., 1998b. A new type of flavour precursors in Vitis vinifera L. cv. Sauvignon blanc: S-Cysteine conjugates. J. Agric. Food Chem. 46, 5215-5219.

Toukis, G., 1974. Chemistry of wine stabilization. A review. In: Webb, A.D. (ed.). Chemistry of winemaking. Advan. Chem. American Society, Washington. pp. $116-133$.

Tsai Su, C. \& Singleton, V.L., 1969. Identification of three flavan-3-ols from grapes. Phytochemistry 8, 1553-1558.

Ugliano, M., 2013. Oxygen contribution to wine aroma evolution during bottle aging. J. Agric. Food Chem. 61, 6125-6136. 
Ugliano, M., Dieval, J.B., Dimkou, E., Wirth, J., Cheynier, V., Jung, R. \& Vidal, S., 2013. Controlling oxygen at bottling to optimize post-bottling development of wine. Prac. Winery \& Vineyard J. 34, 44-50.

Ugliano, M., Dieval, J., Siebert, T., Kwiatkowski, M., Aagaard, O., Vidal, S. \& Waters, E.J., 2012. Oxygen consumption and development of volatile sulfur compounds during bottle aging of two Shiraz wines. Influence of pre- and postbottling controlled oxygen exposure. J. Agric. Food Chem. 60, 8561-8570.

Ugliano, M., Kwiatkowski, M., Travis, B., Francis, I.L., Waters, E.J., Herderich, M. \& Pretorius, I.S., 2009. Post-bottling management of oxygen to reduce off-flavour formation and optimize wine style. Aust. NZ Wine Ind. J. 24, 24-28.

Ugliano, M., Kwiatkowski, M., Vidal, S., Capone, D., Siebert, T., Dieval, J., Aagaard, O. \& Waters, E.J., 2011. Evolution of 3-mercaptohexanol, hydrogen sulfide, and methyl mercaptan during bottle storage of Sauvignon blanc wines. Effect of glutathione, copper, oxygen exposure, and closurederived oxygen. J. Agric. Food Chem. 59, 2564-2572.

Ugliano, M., Kwiatkowski, M., Vidal, S., Capone, D., Solomon, M., Dieval, J.B., Aagaard, O. \& Waters, E.J., 2010. The role of copper and glutathione addition and oxygen exposure in the evaluation of key aroma compounds of Sauvignon Blanc. Poster presented at 14th AWITC, Adelaide.

Usseglio-Tomasset, L., 1992. Properties and use of sulphur dioxide. Food Addit. Contam. 9, 399-404.

Van der Merwe, C.A. \& Van Wyk, C.J., 1981. The contribution of some fermentation products to the odor of dry white wines. Am. J. Enol. Vitic. $32,41-46$

Van Wyngaard, E., 2013. Volatiles playing an important role in South African Sauvignon blanc wines. Thesis, Department of Viticulture and Oenology, Stellenbosch University, Private Bag X1, 7602 Matieland (Stellenbosch), South Africa.

Van Wyngaard, E., Brand, J., Jacobson, D. \& Du Toit, W. J. 2014. Sensory interaction between 3-mercaptohexan-1-ol and 2-isobutyl-3methoxypyrazine in dearomatised Sauvignon Blanc wine. Aust. J. Grape Wine Res. 20, 178-185.
Versini, G., Inama, S. \& Sartori, G., 1981. A capillary column gas chromatographic research into the terpene constituents of "Riesling Romano" (Rhine Riesling) wine from Trentino Alto Adige: Their distribution within berries, their passage into the must and their presence in the wine according to different wine-making procedures. Organoleptic considerations. Vini d'Italia 23, 189-211.

Vivas de Gaulejac, N., Vivas, N., Nonier, M., Absalon, C. \& Bourgeois, G., 2001. Study and quantification of monomeric flavan-3-ol and dimeric procyanidin quinonic forms by HPLC/ESI-MS. Applications to red wine oxidation. J. Sci. Food Agric. 81, 1172-1179.

Vrhovšek, U., 1998. Extraction of hydroxycinnamoyltartaric acids from berries of different grape varieties. J. Agric. Food Chem. 46, 4203-4208.

Wallington, N., Clark, A.C., Prenzler, P.D., Barril, C. \& Scollary, G.R., 2013. The decay of ascorbic acid in a model wine system at low oxygen concentration. Food Chem. 141, 3139-3146.

Waterhouse, A.L. \& Laurie, V.F., 2006. Oxidation of wine phenolics: A critical evaluation and hypotheses. Am. J. Enol. Vitic. 57, 306-313.

Wilderandt, H.L. \& Singleton, V.L., 1974. The production of aldehydes as a result of oxidation of polyphenolic compounds and its relation to wine aging. Am. J. Enol. Vitic. 25, 119-126.

Williams, P.J., Strauss, C.R. \& Wilson, B., 1980. Hydroxylated linalool derivatives as precursors of volatile monoterpenes of Muscat grapes. J. Agric. Food Chem. 28, 766-771.

Williams, P.J., Strauss, C.R., Wilson, B. \& Massy-Westropp, R.A., 1982. Novel monoterpene disaccharide glycosides of Vitis vinifera grapes and wines. Phytochemistry 21, 2013-2020.

Yuan, J-P. \& Chen, F., 1998. Degradation of ascorbic acid in aqueous solution. J. Agric. Food Chem. 46, 5078-5082.

Zoecklein, B.W., Fugelsang, K.C., Gump, B.H. \& Nury, F.S., 1995. Wine analysis and production. Chapman \& Hall, London. 